\title{
Descripción de la dinámica agroproductiva-comercial del subsector café en El Salvador y aproximación al análisis de equidistribución del ingreso generado, 1990-20II
}

Katherine Chiquillo, Nelson Gaitán, Luis Vargas Universidad Centroamericana "José Simeón Cañas" (UCA)

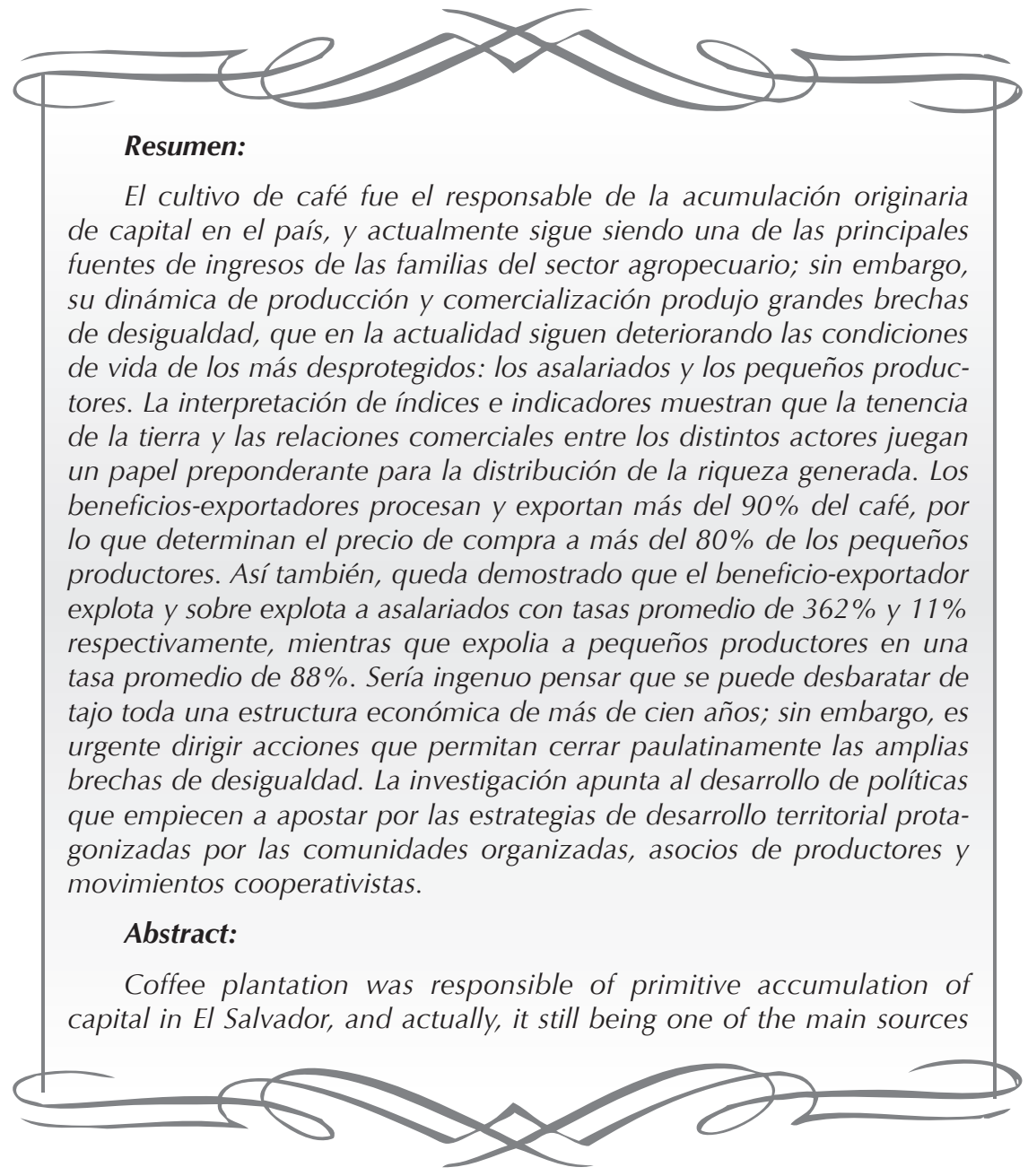




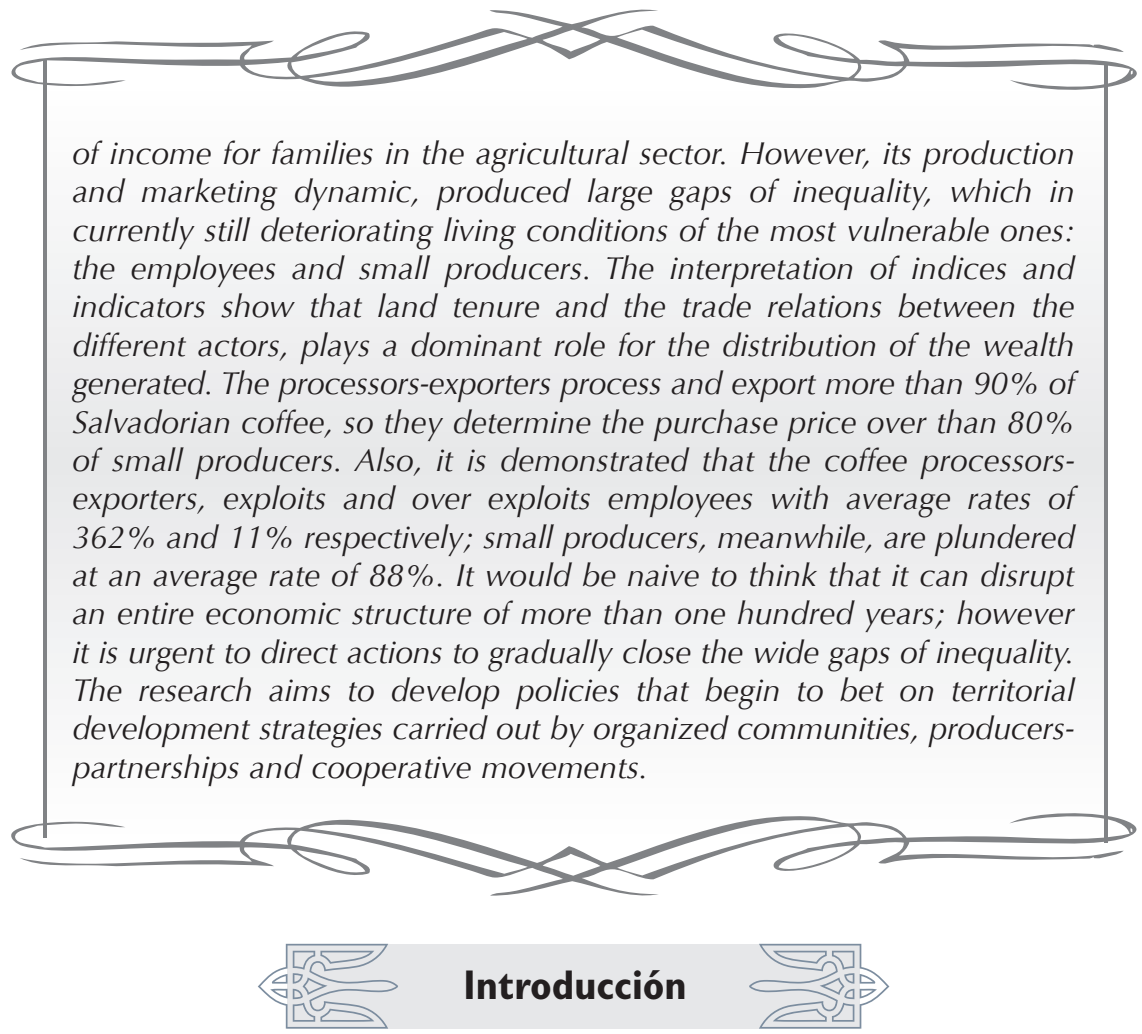

\footnotetext{
L
} a historia del cultivo del café en El Salvador es la historia de la economía de El Salvador desde el siglo XIX. Su desarrollo incipiente generó la acumulación originaria de capital y, solo años más tarde, impulsó un desarrollo nunca antes visto de la infraestructura nacional, apalancó ciudades, dio empleo a millones de personas y puso a El Salvador como referente mundial en la producción del cultivo. No obstante, la fuerza de cambio que el cultivo precipitó en el país, también fue el punto de inflexión en el aparecimiento de grandes brechas de desigualdad entre la población; brechas cuyo catalizador fue la estructura de la tenencia de la tierra y su desigual distribución.

Los virajes que ha tomado la economía de El Salvador desde el siglo XIX, sumado a los shocks externos a los que por naturaleza está expuesta la caficultura, han desbancado al cultivo como aquél que llegó a representar cerca del cien por ciento de las exportaciones y el centro de gravedad de la vida social, política, económica y cultural del país. Sin embargo, el café sigue siendo una de las principales fuentes de empleo en el sector agrícola, 
la generación de valor y divisas, y fuente de servicios medioambientales. Por tanto, el presente estudio busca caracterizar la producción y comercialización del café, utilizando la clasificación que brinda el enfoque de cadenas productivas, apuntando a la descripción de cómo la dinámica agroproductivacomercial incide en la distribución del ingreso generado.

La hipótesis alrededor de la cual giran los esfuerzos empíricos responde a cómo la dinámica de producción y comercialización del café ha causado la pauperización de las condiciones de vida de las familias trabajadoras cafetaleras, acrecentando la brecha distributiva del ingreso generado a favor de los eslabones superiores de la cadena.

El objetivo general perseguido por el estudio fue realizar un análisis de la dinámica agroproductiva y comercial de la actividad cafetalera, dilucidando su influencia en la distribución del ingreso para el sector rural cafetalero, durante el período 1990-2011.

Los objetivos específicos, por su parte, apuntaron a realizar una caracterización de la dinámica de producción, transformación y comercialización del café, haciendo énfasis en la separación de las funciones de cada actor y la forma en cómo éstos se relacionan entre sí. Luego, se muestra cómo el ingreso generado se distribuye entre los actores de la cadena: asalariados, pequeños productores y los beneficiadores-exportadores. Lo anterior, con el objetivo de contribuir al debate de la realidad que presenta el subsector café, la riqueza generada y sus brechas de desigualdad.

El artículo se ha estructurado en tres secciones. En la primera presenta los postulados teóricos que contribuirán a la comprensión del problema desde un enfoque académico; para su elaboración se ha hecho uso de los postulados teóricos clásicos sobre la distribución del ingreso, con especial énfasis en aquellos planteamientos clásicomarxistas que finalmente guían la línea empírica del estudio. Se retoma, como parte de los planteamientos clásicos, la reproducción de la vida como el problema económico fundamental a resolver.

En la segunda, se hace una descripción histórica del cultivo del café en El Salvador, sus actores y las dinámicas que operan. Se ha hecho uso de las fuentes bibliográficas y estadísticas institucionales del Ministerio de Agricultura (MAG), el Instituto Interamericano de Cooperación para la Agricultura (IICA), la Fundación Salvadoreña para las Investigaciones del Café (PROCAFÉ), y el Consejo Salvadoreño del Café (CSC), además de consultas y entrevistas con técnicos especialistas, caficultores, etcétera. 
En la tercera, se presenta una aproximación empírica que, utilizando la información de la segunda parte, bajo los postulados y formulaciones marxistas, busca demostrar que el café genera mucha riqueza monetaria pero la distribución de ésta es en extremo desigual, dificultando las condiciones de reproducción de las personas más vulnerables de este subsector: los asalariados y los pequeños productores. Finalmente, las conclusiones del estudio de acuerdo a los hallazgos que se han hecho a lo largo del desarrollo del tema sobre la distribución del ingreso que genera el café en El Salvador.

\section{Análisis teórico sobre la distribución del ingreso}

En el presente apartado se busca esquematizar, de manera comparativa, planteamientos teóricos básicos sobre la distribución del ingreso bajo las corrientes de pensamiento de la economía política clásica $y$, en contraposición, la corriente neoclásica de la economía. Posteriormente, se hace un recorrido por los principales conceptos de Adam Smith, David Ricardo y Karl Marx, por parte de la economía política clásica, respecto a la distribución del ingreso y sus determinantes, y de igual forma para la escuela neoclásica para establecer la comparación paralela. Luego, habiendo establecido las diferencias entre las dos diferentes corrientes, se concibe un resumen de los conceptos principales en la teoría de la distribución que sostienen los pensadores clásicos: Smith y Ricardo, por su lado; y por el otro, Marx y Aquiles Montoya, siendo estas últimas aportaciones teóricas especialmente eficaces en la explicación de los fenómenos de desigualdad social como se comprueba al final del estudio.

\section{La economía política clásica y la economía neoclásica: diferencia de paradigmas}

Según los pensadores de la economía política clásica, se definen tres clases sociales: capitalistas, trabajadores y terratenientes, por lo que el producto generado en el proceso productivo se distribuye entre estas tres clases sociales según las relaciones que se establecen entre ellos. Caso diametralmente opuesto es la concepción de su contraparte neoclásica, en que no se hace una diferenciación de clases, sino solamente agentes económicos según su rol: consumidores y productores que interactúan en una suerte de mercado abstracto.

La anterior diferenciación es clave para delimitar el objeto de estudio y máxima principal de cada una de las corrientes teóricas. En la economía política clásica, entonces, el problema a resolver es la distribución del producto generado que permita la reproducción de las 
clases. Para el pensamiento neoclásico, abstraídas las clases sociales, el problema se reduce a perseguir la mejor asignación de los recursos que permita la maximización del producto. Así, la abstracción de la visión de clases encajona al estudio de las relaciones sociales de producción que determinan la distribución del producto y las clases mismas, y he aquí un punto de quiebre histórico en toda la ciencia económica que será clave en las acciones de política económica concreta que se tomaron en todo el mundo. El problema de la distribución como fruto de las relaciones sociales de producción abre paso al estudio de un simple problema matemático de equilibrio de la economía entre los productores y consumidores. Las condiciones sociales quedan invisibilizadas.

La distribución del producto social, vista desde el enfoque de la economía política clásica, distingue tres categorías: el trabajo, la tierra y el capital. A cada una corresponde una clase social en la sociedad: el trabajador, el terrateniente y el capitalista, respectivamente, y cada clase recibe una parte del producto o ingreso de acuerdo a reglas establecidas.

El excedente social, único generador de acumulación, se distribuye en forma de ganancias, intereses y rentas a sus propietarios correspondientes; es por eso que, para esta perspectiva de la economía, el uso y monto de este excedente es de enorme importancia y dicta el proceso de expansión de la economía (Harris, 1986: 19). Es importante destacar la concepción clásica según la cual el producto se distribuye entre tres clases, y no cualquier clase, sino clases sociales en virtud de su condición social y económica.

Smith y Ricardo coincidieron en la definición de las categorías entre las cuales se reparte el producto generado por una sociedad y el beneficio, la renta y el salario, respectivamente, como las partes que les corresponden. Coincidieron, además, en la definición del problema económico fundamental a resolver, que es clave para el estudio: las condiciones que posibilitan la reproducción de las clases.

\section{Las relaciones de intercambio marxistas}

A fin de comprender y buscar una explicación a las relaciones de desigualdad entre la mano de obra campesina (representada por el pequeño productor de café y el asalariado) y la clase industrialcapitalista (representada por la industria beneficiadora de café), se hace necesario un desarrollo de los conceptos y categorías marxistas sobre la distribución.

\subsection{Distribución del ingreso}

Marx (1894: 1123, vol. III) expresa que el valor global que se 
produce anualmente es distribuido por el capitalista puesto que es él quien extrae el plustrabajo. A partir de esto, el plusvalor se reparte en ganancia, renta de la tierra y salario entre las tres clases anteriormente mencionadas: la clase capitalista, terrateniente y obrera.

El autor, además, sostiene que una vez supuesta la producción social de cualquier tipo, se puede diferenciar la parte del trabajo cuyo producto es consumido directa e individualmente por los productores y allegados y la parte que es plustrabajo ocupado para satisfacer las necesidades sociales generales. Es decir, que para cualquier forma de producción, es necesario entregar una parte del producto generado para la reproducción de la fuerza de trabajo, mientras que lo demás es utilizado por las otras clases sociales.

Sin embargo, el análisis científico del modo capitalista demuestra que el modo de producción es el fruto histórico y está condicionado, a la vez, por el desarrollo de las fuerzas productivas sociales; y que esta evolución de las relaciones, es a la vez resultado histórico de un proceso precedente del cual parte el nuevo modo de producción. Estas relaciones, entonces, tienen un carácter específico, histórico y transitorio, y finalmente las relaciones de distribución son en esencia las relaciones de producción (Marx, 1894: 1114, vol. III).
Dicho esto, Marx (1894, 1115, vol. III) en el último tomo de su obra El Capital enuncia que el producto anual no se distribuye en salario, ganancia y renta de la tierra, sino en capital y en réditos (o ganancias que rinde el capital). Una parte de ese rédito toma la forma del salario; sin embargo, aclara, que solo toma esa forma luego que el obrero es enfrentado al capital. Es decir, que el carácter social de la relación obrero-capitalista está determinado por la condición de los obreros desposeídos de medios de producción o de consumo y por la condición de la clase capitalista de poseedores de las condiciones de trabajo. Por lo consiguiente, si una parte del producto no llegara a transformarse en capital, es imposible que la otra parte se asuma como salario, ganancia y renta. Esto es lo que sucedió con el despojo de las tierras comunales y ejidales en El Salvador, que permitió la concentración de los medios de producción en pocas manos y resultó en una creciente y desposeída masa de trabajadores necesitados del sustento. Es decir, al tener a trabajadores libres es cuando aparecen las formas asalariadas que amarran al trabajador al proceso de producción capitalista.

Ahora bien, es necesario hacer una distinción que surge de la posibilidad real que la situación ocurra: que el trabajador sea remunerado por debajo del valor de su fuerza de trabajo, siendo así que el 
capitalista logra mayores márgenes de acumulación y el obrero, una pauperización de su vida y la de su familia.

\subsection{Explotación y sobrexplotación de la fuerza de trabajo}

El análisis del sector agrícola, principalmente, permite reflexionar sobre estos dos conceptos, que posteriormente ayudarán a explicar la realidad del subsector cafetalero: la existencia de explotación, en tanto median relaciones salariales entre el eslabón beneficiador-exportador y los trabajadores que venden su fuerza de trabajo, y además sobrexplotación en su proceso de producción, transformación y comercialización, en tanto se les remunera por debajo de su valor (Montoya 1980: 21).

\subsection{La subsunción del trabajo en el capital}

Marx reconoce la existencia de distintas formas de producción; sin embargo, dentro de una sociedad, una determinada forma de producción adquiere un carácter dominante al momento de asignar a las otras su jerarquía e influencia, de manera que la relevancia que puedan tener las otras formas de producción estará sometida a la "principal", es decir, subsumidas. La subsunción se distingue entre directa e indirecta, como se amplía a continuación. Ambos tipos de subsunción, como se evi- denciará después, se hacen presentes en la dinámica cafetalera y en ese sentido se hace necesario ilustrarlos en los siguientes apartados.

La subsunción directa del trabajo en el capital puede verse bajo dos lupas: la subsunción formal y la subsunción real. En el momento en que el capital se apropia del proceso de trabajo, puede bien alargar la jornada laboral acudiendo al mecanismo de plusvalía absoluta, y en tal escenario se afirma que el trabajo está formalmente subsumido en el capital; o bien puede darse un incremento en la capacidad productiva del trabajo que acorte la parte de la jornada laboral que pertenece al trabajador $y$, consecuentemente, se prolongue la parte de la jornada laboral durante la cual se produce la plusvalía, y nos encontramos en este caso frente a la subsunción real del trabajo en el capital (Montoya, 1998: 162).

Las formas de producción no capitalistas, tales como la producción de valores de uso para el autoconsumo y la producción y circulación simple de mercancías, se encuentran subordinadas de forma indirecta al capital cuando estas formas de producción son convertidas en instrumentos mediatos de valorización del capital y no se relacionan por medio de salarios, al mismo tiempo que las subordina exige y posibilita su existencia sin modificarles su lógica propia (Montoya, 1998: 164). 
Para que exista un proceso de subsunción indirecta es necesario que exista una relación de expoliación, y ésta se manifiesta cuando el capital expropia a los productores no capitalistas de una parte de su trabajo sin que exista entre ambos una relación directa en el proceso productivo, es decir, una relación salarial (Montoya, 1998:165). En El Salvador, la alta concentración en la propiedad de la tierra ha significado también una producción en exceso minifundista, y que se ve subsumida indirectamente en el capital, en tanto produce y entrega su producto actores con lógica operativa capitalista.

La expoliación es un concepto de interés especial para describir la condición de los productores individuales y pequeños productores que utilizan mano de obra familiar, ya que su trabajo no se encuentra subsumido de forma directa en el capital. También se utilizarán los conceptos de explotación y sobre explotación del trabajador asalariado para demostrar la voracidad de la clase capitalista a la hora de entregar una parte del producto generado para la reproducción de la fuerza de trabajo, la pauperización de las condiciones de vida de los pequeños productores de café y el aumento en la brecha de distribución de los ingresos generados a través de la descripción de la dinámica agroproductiva y comercial del café en El Salvador.

\section{Evolución del cultivo del café en El Salvador}

El café representa uno de los principales productos de exportación que se produce en el sector agropecuario de El Salvador, además vislumbra una amplia base social para el país, ya que para el año cafetalero 2009/2010 el rubro generó un aproximado de 75,000 empleos permanentes y más de 18 millones de jornales, al mismo tiempo la caficultura representa la fuente principal de ingresos para más de 20.000 caficultores (PROCAFÉ, 2010).

En el presente apartado se hace un recorrido por los antecedentes de la dinámica de producción y comercialización del café, con el fin de evidenciar su importancia económica y social desde principios del siglo XX hasta 1980, retomando la conjugación de reformas y leyes que, junto con la instauración del sub-sector en el país, dieron paso a un panorama de desigualdad entre los diferentes actores participantes; este proceso, que claramente se ve dividido entre productores y beneficiadores/exportadores, genera una dinámica con desigual participación.

En la segunda parte se busca describir la dinámica agroproductiva y comercial del sub-sector café en El Salvador, el cual se realiza utilizando la clasificación (no el 
enfoque) de cadena agroproductiva, que si bien no se centrará en analizar los procesos que implican la comercialización externa, se analiza brevemente el contexto mundial en el que se mueve el café salvadoreño. Seguidamente, una caracterización de la dinámica productiva en la que se destaca la necesidad de caracterizar las cooperativas de la reforma agraria, como fenómeno dentro del sector, que tiene amplia participación y aporte en la generación de bienestar social. Se caracteriza la dinámica de transformación y comercialización como dos procesos articulados en uno. La tercera y última parte permite concluir la importancia del café desde la perspectiva de la sostenibilidad económica, social y ambiental, no solo para los actores que participan dentro del sub-sector, sino también para la población salvadoreña en su conjunto.

\section{Antecedentes históricos}

En la década de los sesenta se lleva a cabo un proceso de diversificación económica, lo cual comienza a dejar al agro lejos de su papel protagónico dentro de la economía salvadoreña. La década de los ochenta se resalta por ser una época en donde el sector agropecuario sufre la pérdida de importancia relativa más marcada. Esto se debe en parte al crecimiento considerable del comercio y los servicios, aunado con el inicio del conflicto armado y un significativo cambio en los precios relativos de los productos agropecuarios (Boyce, 1999).

Las condiciones históricas del desarrollo del café en El Salvador permitieron un alto grado de concentración de tierras dedicadas a este producto, situación que dio pie a que las más poderosas familias terratenientes tuvieran participación en toda la cadena agroproductiva y se convirtieran en dueñas del proceso productivo completo, incluyendo el beneficiado del café y su exportación. Dicha situación persiste aún después de la reforma agraria impulsada en la década de los ochenta, presentándose un mercado oligopólico en el beneficiado y exportación del café; además, El Salvador se vuelve precio aceptante del nivel internacional de precios, lo que acentúa la separación del productor con la economía real. Es así como la casi totalidad de caficultores, para exportar su producción, se ven obligados a recurrir al proceso agroindustrial del beneficiado del café, siendo los beneficios/exportadores los que canalizan más del $90 \%$ de exportación de café al exterior y también quienes se quedan con la mayor parte del valor agregado y de las divisas que su comercio genera, configurándose así una situación de desigualdad persistente en la distribución de los ingresos en el sector rural cafetalero.

No obstante, en el proceso de investigación, se ha identificado el fenómeno de las cooperativas como organizaciones protagonistas, en 
muchos casos, de toda la cadena agroproductiva, es decir, que producen, transforman y exportan su café; aunado a ello, han sido medios de generación de bienestar económico y social a sus socios y comunidades. Las cooperativas cafetaleras cuentan con una larga trayectoria, y desde sus procesos de formación, en el marco de la reforma agraria, han buscado protagonismo como entidades sociales que no solo han vivido procesos duros de transformación e inserción dentro del sector, sino también se han visto afectadas fuertemente por la crisis de inicios del siglo XXI.

En los períodos presidenciales comprendidos entre 1994-2009 se evidencia la pérdida deliberada de importancia del cultivo del café dentro de las políticas públicas salvadoreñas, enmarcada en el proceso de diversificación económica que se viene formando desde la década de los sesenta; la estructura monoexportadora pierde su papel protagónico y el café su importancia relativa dentro de la economía salvadoreña. Es hasta en el último período presidencial que la atención del gobierno vuelve al sector agropecuario, en el cual el sub-sector café es incluido como cultivo a ser reactivado, fortalecido y desarrollado; aunque es necesario aclarar que, actualmente, este plan de rescate a la caficultura nacional es escasamente un proyecto ejecutándose en su primera fase, con aproximadamente 6 meses de ejecución.
Es importante vislumbrar la evolución del subsector como parte del ensamblaje del sistema capitalista en El Salvador, un producto que no solo ha resultado ser verdaderamente prolífico para una específica clase social, sino que la magnitud de su éxito marcó la formación económico-social del país en su momento; aunado a ello, las erróneas reformas y políticas aplicadas al sector, en conjunto con el arrastre de una mora financiera y las crisis de los precios, han deteriorado fuertemente a la caficultura en El Salvador.

\section{Descripción de la dinámica agroproductiva y comercial del cultivo del café en El Salvador}

El cultivo del café ha sido clave y trascendental, no solo por su importancia en indicadores macroeconómicos, sino también por participar dentro del tejido social, cultural, institucional y político de El Salvador. A lo largo de la historia ha sido un rubro tradicional, considerado rentable y la base de encadenamientos de mucho valor agregado, por las múltiples transformaciones que sufre el grano.

Hoy, la dinámica generada en los sectores productivos de un sistema económico es determinada por las relaciones existentes entre los actores que participan dentro de eslabones que conectan las etapas del proceso. Estos eslabones son parte de las denominadas 
cadenas productivas, y se ven al mismo tiempo influenciados por un entorno determinado con políticas, cultura, ambiente, instituciones de apoyo, instituciones de investigación, entre otros. Así pues, en las cadenas productivas se encuentran presentes agentes claves, y con ellos una serie de trabajos diferenciados según el estado del producto que se esté modificando, todo ello con el fin de vincular procesos que van desde la pre-producción hasta la comercialización.

El enfoque de cadenas productivas logra engendrar sus primeros conceptos y desarrollo teórico en el marco de un paradigma económico distinto al planteado como referente para el análisis empírico de esta investigación. Por tanto, en el presente análisis del sub-sector café, no se pretende aplicar la teoría que propone el enfoque, únicamente utilizar su clasificación, y con ello explicar la dinámica del sector en el sentido de "cadena", a fin de describir y caracterizar las funciones, conexiones y sinergia de cada uno de sus eslabones y su relación con el entorno.

El café es considerado clave para el desarrollo de países productores; representa el producto más comercializado en el mundo superado solo por el petróleo, además es el producto bebible más consumido después del agua. La dinámica de producción mundial de café constituye una fuente vital de empleo e ingresos para 25 millones de per- sonas y es para algunos países una fuente crucial para el sostenimiento de servicios medioambientales (Laínez, 2011: 12). Es esencialmente un commoditie, y su precio es resuelto en las bolsas de mercados a futuros específicamente en el contrato " $\mathrm{C}$ " transado en el mercado de Nueva York. Debido a que en estas negociaciones de contratos no solo convergen productores y compradores, sino entran en juego inversionistas y especuladores, se disminuye del precio el vínculo a la economía real; y esto bien se traduce en épocas de bonanza cafetalera o en periodos en donde el precio se deprime y los productores no alcanzan a cubrir sus costos de producción.

En consecuencia, el mercado mundial y los precios que se conciben en la economía bursátil del mercado externo dictan los precios de compra-venta en el mercado nacional, por lo que las relaciones sociales que se generan entre actores de los distintos eslabones de la cadena se ven influenciadas por este entorno externo que tiene su propia estructura de políticas y leyes que regulan y dictan el comportamiento de sus economías. Además, incluye un esquema cultural con patrones distintos a los nacionales, dictando comportamientos de consumo $y$, con ello, variaciones entre oferta y demanda. Esto evidencia que los eslabones que componen la cadena interna de agroproducción y comercialización están directamente vinculados con el entorno internacional. 


\section{Cadena agroproductiva del café}

Tal cual se ha analizado anteriormente, el destino de la producción de café en El Salvador es, y ha sido desde sus inicios, principalmente para la exportación, y en los últimos 10 períodos su cosecha se ha exportado en promedio el $90 \%$ del total de lo producido, indicando que la dinámica interna a lo largo de toda la cadena agroproductiva depende y se ve grandemente influenciada por las tendencias y la volatilidad de los precios del mercado internacional; sin embargo, y pese a esta dependencia, en la presente investigación la descripción de la dinámica agroproductiva y comercial se centrará en identificar las relaciones e impactos generados en el sector cafetalero nacional, es decir, no se hará énfasis en analizar la dinámica de comercio exterior, pues para ello se tendría que realizar un análisis de actores y dinámicas concebidas en estructuras económicas y sociales ajenas a las del país.

Para efecto de análisis posteriores, y con el fin de comprender la idiosincrasia en los procesos de producción, transformación y comercialización del café, se ha estructurado un esquema que explica las etapas del proceso productivo del café. En la figura 1, se puede observar a groso modo las etapas por las que atraviesa el café para poder llegar a ser un bien de consumo final. La forma de procesar y consumir el grano de café ha sufrido distintos cambios desde sus orígenes, y ha estado determinado por acontecimientos pasados. No obstante, hoy existe un proceso de transformación del grano para que éste pueda convertirse en un bien de consumo final, y por su misma naturaleza concibe distintas etapas de transformación que llevan al grano a distintos estados, que van desde el grano-uva (el cual se obtiene en la etapa del cultivo y recolección), grano en pergamino y granooro (en la etapa de transformación correspondiente a la etapa de pergaminado y/o beneficiado) y el grano tostado (obtenido de la etapa de torrefacción) finalmente es transformado en bebida o consumido según las propias costumbres de cada país que lo importa y consume.

\section{Figura 1}

\section{Etapas del proceso productivo del café como bien de consumo final}

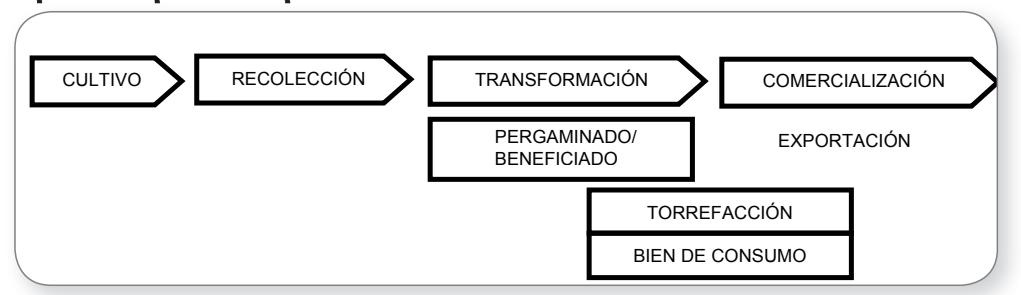

Fuente: elaboración propia con base en investigación de campo. 
En la búsqueda de brindar un esquema estructurado que sirva para distinguir los actores que participan en el sistema de producción cafetalero, se ha elaborado una segunda figura que divide el pro- ceso principalmente en dos fases, observándose en la figura 2 que cada eslabón de la cadena genera diversos productos que son insumos para iniciar el proceso del eslabón siguiente.

\section{Figura 2}

\section{Cadena agroproductiva del cultivo de café en El Salvador 2012}

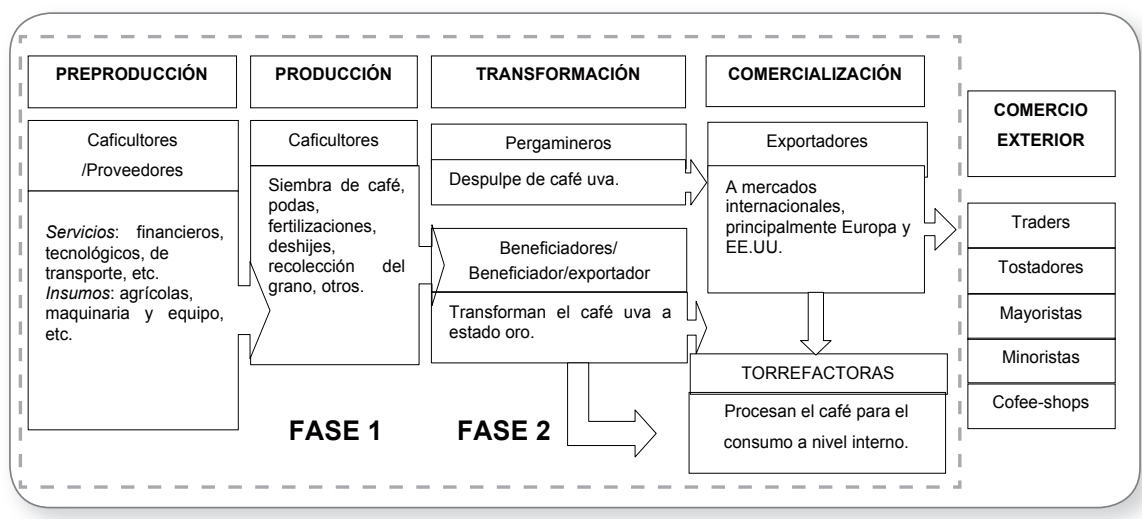

Fuente: Elaboración propia con base en datos del "Conglomerado del café en El Salvador, 2002" e investigación propia de campo.

La cadena agroproductiva y comercial del café permite apreciar a detalle el proceso productivo que se genera. Con el fin de conocer el comportamiento de los grupos de actores sociales identificados en la dinámica y comprender mejor sus relaciones formales e informales, además del grado en que sus acciones afectan el desempeño del conjunto y la distribución del ingreso, a continuación se describe, a través del análisis de variables macroeconómicas y elementos claves, cada una de las etapas de la cadena por eslabones, que para efectos de análisis se han agrupado en dos gran- des fases: la dinámica productiva y la dinámica de transformación y comercialización.

En la primera fase de la cadena agroproductiva del café, se identifican los eslabones de preproducción y producción, por ser las dos etapas previas al proceso de transformación (el estado del grano al finalizar esta denominada fase 1, es en uva). En el eslabón de pre-producción del café, se desarrolla toda la gama de actividades y servicios que anteceden al cultivo y que sirven como preparación para el desarrollo de la fase 
de producción. Por tanto, en esta fase se reconoce a los caficultores como los actores de la producción, quienes en la etapa previa obtienen insumos y servicios de proveedores.

En el proceso de pre-producción pueden identificarse todas las actividades destinadas a la siembra de plantas de café, entre las que se tiene la preparación del terreno, trazado, ahoyado y finalmente siembra; no obstante, en El Salvador la renovación y/o repoblación del parque cafetalero, en general, no ha sido una prioridad para el sector, pues en la actualidad el $90 \%$ del mismo registra una edad promedio de entre 35 y 40 años, siendo una de las causas principales de la caída en los índices de productividad (CSC, 2012).

La fase de producción es la más relevante si se pretende analizar el impacto que tiene el cultivo en el ingreso de la población rural, ya que este eslabón lo ocupan más del $85 \%$ de los productores de café, que son los que generan la materia prima en la fase agrícola para luego ser transformada. La producción de café experimenta un comportamiento cíclico, ya que ha presentado decrecimientos, crisis, recuperaciones y auges a lo largo de la historia; sin embargo, actualmente la producción nacional se ha visto grandemente disminuida, acompañada con pérdidas en la productividad, pudiéndose encontrar las causas en sucesos coyunturales generados tanto a nivel nacional como internacional. Esta serie de procesos se incrementan debido a efectos tales como: el endeudamiento que desde entonces el sector empieza a adquirir -y que hasta la fecha representa uno de los principales cuellos de botella para los productores- y la prolongada pérdida de rentabilidad.

Según datos del CSC y la Dirección General de Estadísticas y Censos (DIGESTYC), el área cultivada de café ha presentado disminuciones en tres períodos distintos, el período cosecha 1995/96 disminuyó 2,900 manzanas, mientras que para el período 2001/02 disminuyó 1,830 manzanas, y finalmente en el período 2007/08 se registra la última caída con un total de 12,293 manzanas menos de café cultivadas, lo que representa una disminución del $7 \%$ de área cultivada con respecto al período de 1992/93. Para el caso de la producción y la productividad, se evidencia una disminución significativa en el período analizado, y es que del período cosecha 1992/93 hasta el período 2009/10 la producción nacional ha disminuido 2,806,200qq. oro uva, lo que representa una disminución del $65 \%$ versus una disminución del $62 \%$ de productividad para el mismo período.

Por otra parte, el bosque cafetalero de El Salvador cuenta con una superficie total de $217,628 \mathrm{Mz}$. Se tienen registros de la existencia de 
16,995 productores, de los cuales el $55 \%$ poseen entre 0 y $3 \mathrm{Mz}$. Este rango representa únicamente el $6 \%$ del total de la superficie cafetalera, es decir que aproximadamente este $55 \%$ de los productores de café poseen el $6 \%$ del total del área cultivada, mientras que un $2 \%$ de los productores de café posee fincas comprendidas entre $100.1 \mathrm{Mz}$ a más, con una representación del $32 \%$ del total de la superficie cafetalera (PROCAFÉ, 2010).

El $80 \%$ del total de productores pertenece al estrato de pequeños productores, poseen el $19 \%$ del total de la superficie. Aunque aproximadamente la mitad del to- tal de éstos apenas poseen el 6\% de la superficie, su aporte fue de un $12 \%$ al total de la producción para el período 2009/2010. Por otro lado, el $15 \%$ del total de productores pertenece al estrato de medianos productores, con un total del $30 \%$ de la superficie cafetalera y un aporte del $23 \%$ en el períodocosecha analizada. Finalmente, el último $5 \%$ del total de productores pertenece al estrato de grandes productores, que poseen el $51 \%$ de la superficie y aportaron un $65 \%$ de la producción al mismo período. Este análisis responde a una relación de tenencia de la tierra versus productores que puede verse gráficamente de la siguiente manera:

Figura 3

Estratificación de productores por tenencia de la tierra

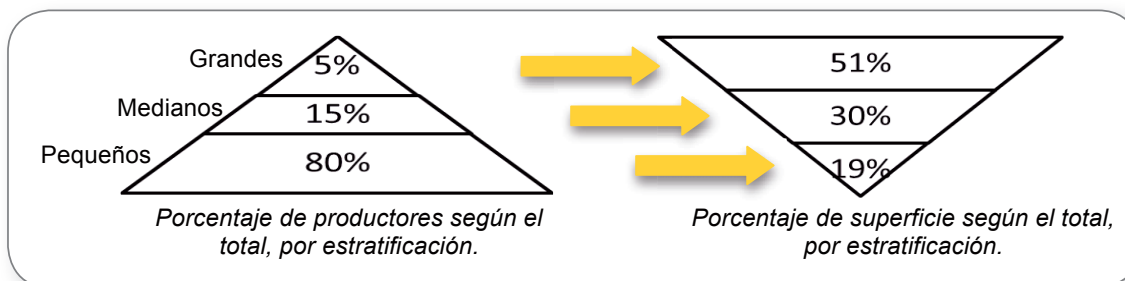

Fuente: Elaboración propia con base en datos del boletín estadístico de PROCAFÉ 2010.

Según la clasificación del número de caficultores por rango de tamaño de finca -se puede observar respecto con el aporte que tienen los productores a la producción nacional para el período 2009/2010-, se tiene que 8,790 productores aportaron el $3.7 \%$ a la producción total de este período, mientras que únicamente 136 productores aportaron un $31 \%$ de la producción total.

En El Salvador, los 8,790 pequeños productores se dedican al cultivo con extensiones de finca de entre 0.1 y 3 manzanas, los cuales forman parte de un estimado de los 25 millones de pequeños producto- 
res que cultivan aproximadamente el $75 \%$ del café mundial, por lo que las variaciones en los precios repercuten sensiblemente en sus condiciones de vida, principalmente de éstos pequeños productores (ICAFE, 2005). La principal característica de los pequeños productores es que su producción se basa en la maximización de la utilización de la mano de obra familiar y en formas asociativas de producción basadas en principios del cooperativismo y no tanto en la lógica de lucro. También es necesario comprender que la estructura productiva del sub-sector café es tan vulnerable como cualquier otro cultivo agrícola ante la presencia de fenómenos naturales, pero quienes se dedican o emplean en actividades de producción de café, por ser un cultivo meramente de exportación y cuyos precios se determinan en el mercado bursátil, son doblemente vulnerables.

Hasta la etapa de generación del grano uva termina un proceso dentro del esquema productivo en el cual se da una primera etapa de comercialización, que si bien el grano de café no se encuentra en el estado en el cual es dirigido al consumidor final, hasta este punto los pequeños y medianos productores nacionales pueden ser protagonistas y parte de la cadena agroproductiva, pues se ven completamente ajenos en los siguientes procesos de transformación y comercialización del grano. A pesar de ello, en el proceso de investigación del presente documento se han identificado esquemas asociativos compuestos principalmente por pequeños $y$ medianos productores que han demostrado mantener la participación productiva y comercial a lo largo de toda la cadena.

A nivel nacional, solo las cooperativas de café se dedican a la producción para la exportación, son las que más socios agrupan y tienen más historia y experiencia en su actividad, debido a que se conformaron hace ya muchos años. Según un estudio realizado al sector cooperativo por el Banco Centroamericano de Integración Económica (BCIE), con una muestra de 58 instituciones del sector agropecuario y pesquero, las cooperativas de café resultan ser las más rentables. Las conclusiones del estudio indican que las cooperativas de cafetaleros son las más organizadas y con la experiencia más consolidada entre las organizaciones del sector agropecuario. Las cooperativas del sector cafetalero resultaron estar integradas por un número mayor de socios y registran las productividades más altas. Así también, presentaron estructuras mejor definidas y mejores organizaciones del trabajo en todos sus aspectos, desde la producción, a través del procesamiento, hasta la comercialización del producto final, incluso en sus gestiones económicas y financieras (BCIE, 2009). 
Las cooperativas brindan beneficios a sus miembros a través de la consecución de precios más altos, beneficios sociales para sus socios, entre otros, por lo que en lo que sigue se busca analizar la importancia de las Cooperativas Cafetaleras del Sector Reformado (CCSR) ${ }^{1}$ a nivel de sus principales indicadores estadísticos y con ello obtener una pequeña caracterización, buscando tener más claro el panorama de su peso y participación dentro del sector y no olvidar su importancia a la hora de estructurar políticas sectoriales.

Al finalizar los procesos de producción, la etapa termina con la recolección del grano uva, que pasa a manos de los transformadores $y / 0$ comercializadores del café en El Salvador. De aquí en adelante se genera un nuevo proceso correspondiente a esquemas agroindustriales, en los cuales el $80 \%$ de productores catalogados como "pequeños" no tienen participación. Ellos responden a la venta de su producción y aceptar el precio denominado "precio pagado al caficultor", del cual se realizan los descuentos por el canon de transformación, descuentos por el porcentaje de grano defectuoso (merma), transporte, descuentos financieros correspondientes a los préstamos de avío o deudas con el Fondo de Emergencia para el Café (FEC) o con el Fideicomiso Ambiental para la Conservación del Bosque Cafetalero (FICAFE) y los descuentos correspondientes a la investigación tecnológica (US\$0.50) y para financiar al CSC (US\$0.30).

Es importante mencionar que los descuentos correspondientes al canon de transformación, transporte (hasta el recibidero o beneficio) y porcentaje de merma, son montos calculados según las políticas internas de cada empresa beneficiadora, por lo que las bases para el cálculo de estos cobros no son información de acceso público y se desconoce la estructura bajo la cual son estimados, y, por tanto, lastimosamente se hace de análisis complejo para el apartado III.

A nivel nacional, la mayoría de actores que benefician el café son también quienes lo exportan, entendido éstos como el grupo social compuesto por personas naturales o jurídicas que explotan directamente, en calidad de propietarios o arrendatarios privados, los medios de producción donde se realiza el proceso industrial destinado a transformar café uva, cereza seca o pergamino, en café oro (Rivas, et al., 2011). Según este autor, se utiliza el criterio de explotación y no el de propiedad para excluir a los propietarios de los beneficios que no se dedican al usufructo directo, sino mediante un canon de arrendamiento, lo cual los excluye de todo riesgo inherente al proceso productivo y comercial del grano. Dentro de la cadena agroproductiva del café también se pueden identificar pergamineros que procesan 
el café hasta estado pergamino, realizan actividades de compra a productores y ventas a trilladores y beneficiadores/exportadores. La mayoría de estos actores realizan el proceso de forma artesanal y el volumen procesado es mínimo en comparación a los volúmenes de producción que procesa el grupo de beneficiadores/exportadores (Zúñiga, 2002). A pesar de su baja contribución y participación dentro de este proceso de transformación, el CSC registra 318 beneficios pergamineros en todo el país, hasta mayo de 2012, evidenciando el impacto que tiene esta práctica en la generación de ingresos de los pequeños que participan en esta dinámica.

Dentro del proceso de beneficiado están los participantes que obtienen la mayor parte de la producción, proveniente en mayor proporción de los productores. Estos actores protagonistas del eslabón de transformación y comercialización son los denominados beneficiadores/exportadores. Para el año 2012, el CSC tiene 102 beneficios registrados, y en la actualidad se encuentran funcionando 82. La capacidad instalada de ellos es variable: se encuentran desde una capacidad de procesamiento de 1,500 y más de 250,000 quintales oro. Una cantidad considerable de ellos no hace uso de la totalidad de su capacidad y almacenamiento; otros también son torrefactores y comercializan café tostado y molido con su respectiva marca en el interior del país (CSC, 2012).
Dentro de la dinámica de comercialización, un productor de café obtiene como resultado final el café en uva y éste es comercializado a quienes realizarán el proceso de transformación: los pergamineros y beneficiadores/exportadores. El producto obtenido al final de este proceso es café en pergamino o café oro verde, cuyo destino es la exportación. La comercialización externa es ejercida por exportadores autorizados por el CSC, quienes negocian el café con una gama de compradores en el exterior del país; los destinos del café varían en su participación, todo depende de las condiciones de demanda y precio (Rivas, 2011).

La dinámica de comercialización evidencia una estructura de precios pagados al caficultor y precios de venta que son los precios determinados en el contrato " $\mathrm{C}$ " de la bolsa de Nueva York. Para entender la razón por la cual se manejan dos clasificaciones de precios es necesario analizar el proceso de comercialización interna, en la que la negociación del café se da entre productores y agentes de transformación y/o comercialización, como los exportadores, beneficiadores/ exportadores, agentes de los beneficiadores/pergamineros, tostadoras locales e intermediarios. La comercialización la realizan productores con base en disposiciones resultado de ventas externas que pueden ser sobre la base de cupos que sirven como referencia para regular 
su venta o puede ser sin regulación, permitiéndole al productor vender como lo desee (Rivas, 2011).

El cálculo del precio nacional se deriva del precio cotizado en el sistema financiero internacional; el precio de referencia, que en el caso de los café arábicas es negociado en la bolsa de Nueva York, se le aplican diferenciales de venta que se pueden obtener en función de la calidad, la oferta, la demanda y la disponibilidad, ya sea para aumentar o disminuir el precio de referencia. Aplicada esta variación, se le resta el porcentaje de cobro del CSC y PROCAFE, menos costos financieros abonados al FEC, en caso hayan optado al fondo y aún lo sigan pagando, y finalmente se resta el porcentaje del costo de los beneficios por transformar el grano. Cabe mencionar que este porcentaje de costo lo calcula cada beneficio, $y$ en el proceso de investigación fue imposible obtener un dato estimado. Asimismo, algunos productores y/o cooperativas tienen que abonar sus deudas a FICAFE $\mathrm{O}$ a otras instancias financieras. Es importante señalar que, si bien esta estructura de cálculo del precio nacional incluye la aplicación de diferenciales, nos lleva a concluir que este precio no es el efectivamente pagado al productor, ya que según se ve en la práctica real, los diferenciales se negocian con los compradores externos a los cuales no tienen acceso los pequeños productores, ni cuentan con la infor- mación suficiente para entender la dinámica de obtención de precios o información de mercado que les permita negociar ser parte de estos diferenciales.

Así también, como parte de la dinámica de comercialización, en El Salvador existen actores que intervienen en el proceso de torrefacción, el cual genera como producto el café tostado en grano, el café tostado molido y café soluble, todo en diferentes presentaciones. En el mercado nacional existen 45 tostadores de café registrados en el CSC para 2012 (entre pequeñas, medianas y grandes empresas) que tuestan y venden el café en diferentes presentaciones dentro y fuera del país. Entre las empresas torrefactoras nacionales más reconocidas en el mercado nacional están: QualityGrains S.A. de C.V., Planta de Torrefacción de Café V (Plantosa), Comercial Exportadora (COEX), Cooperativa de Cafetaleros de San José de La Majada de R.L., Sociedad Cooperativa Cuzcachapa de R.L., Sociedad Cooperativa de Cafetaleros de Ciudad Barrios de R.L., entre otras (TECHNOSERVE, 2008).

En consecuencia, todo el flujo de procesos, dinámica e interrelaciones han sido descritas con el fin de elaborar indicadores económicos que evidencien cuál ha sido la participación de la población rural en la distribución del ingreso generado dentro del sub-sector café en El Salvador. 


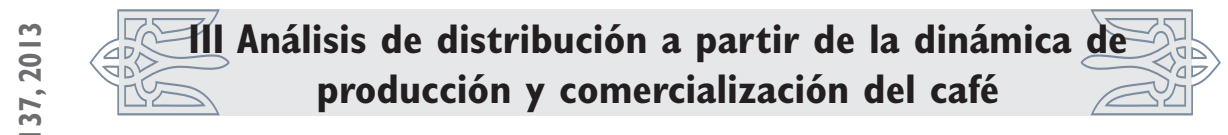

En el apartado II se describe a detalle la dinámica cafetalera utilizando la clasificación de cadena productiva y eslabonamiento. En este tercer y último apartado, en aras de la validación de la hipótesis, se hace necesario realizar un análisis de la distribución del ingreso que genera la dinámica cafetalera y cómo sus dinámicas internas determinan las proporciones en las que el producto generado se subdivide. Así pues, se pretende mostrar los destinos del ingreso generado por el café, circunscribiendo el análisis únicamente para la dinámica de producción y comercialización interna. En ese sentido, y haciendo uso de la clasificación de encadenamiento detallada, se analiza la situación de la distribución en el período 1990-2011 o, en su defecto, para los años en que haya disponibilidad de datos, en los actores siguientes: Asalariados y pequeños productores, en sus situaciones individuales como eslabones, pero también en su relación con el eslabón superior en análisis de la cadena: los beneficios-exportadores.

\section{Supuestos del análisis empírico}

La divulgación de información estadística del subsector cafetalero es relativamente amplia; no obstante, la dificultad de contar con datos específicos que permitieran un aná- lisis más desagregado ha llevado a la necesidad de formular una serie de supuestos bajo los cuales se ha tratado la información estadística. Aun así, las dinámicas mantienen su esencia y las relaciones descubiertas están en concordancia con lo planteado por la teoría marxista de la distribución del ingreso.

a. La población asalariada en el sector no se involucra en el cultivo del fruto uniformemente todo el año. En promedio, se toman seis meses de trabajo remunerado, tomando en cuenta los meses intensivos, octubre a enero, y el resto de meses de menor actividad.

b. El rendimiento de los cultivos, los periodos de cosecha y periodos de manejo de finca serán, para efectos de estudio, iguales en todas las regiones del país.

c. Debido a la falta de un salario promedio para el sector cafetalero, se utilizará como variable proxy el salario mínimo rural. Se asume que los asalariados reciben exactamente esta cuantía en pago por su fuerza de trabajo.

d. El pequeño productor de café será aquel que produce bajo ninguna relación salarial, ocu- 
pando únicamente su fuerza de trabajo y la de su familia para la producción de sus terrenos, y con menos de 10 manzanas de tierra para el cultivo.

e. El asalariado puede en ocasiones ser también pequeño productor, pero a efectos de este estudio se distinguirán como dos actores diferentes. El asalariado no es pequeño productor, ni viceversa.

Se vuelve a aclarar que, contrario a la lógica reduccionista de los análisis empíricos neoclásicos, los supuestos de este capítulo se utilizan únicamente con el objetivo de hacer posible el tratamiento de los datos estadísticos para mostrar las relaciones descubiertas.

\section{Asalariados}

El análisis empírico se inicia con aquéllos que solo disponen de su fuerza de trabajo como medio de subsistencia y cuya posición social y económica los ubica en primer eslabón de la clasificación de la cadena productiva. A su participación en el ingreso total le denominaremos la masa salarial.

Según la Encuesta de Hogares de Propósitos Múltiples (EHPM) 2010, la población ocupada dentro de este subsector es solamente el $15 \%$ de la Población Económicamente Activa Rural (PEAR). Dentro del ramo de agricultura, ganadería, caza y silvicultura, este porcentaje de participación asciende al 57\%, es decir, casi seis de cada diez asalariados de esta rama corresponde a personas cuyo salario es producto de la actividad cafetalera. Es pues una actividad fuerte en la generación de empleo y, por tanto, se hace importante estudiar la masa de ingreso a la que este grupo de personas tiene acceso.

La masa salarial del subsector representa solamente el $5 \%$ de la masa de salarios de la PEAR. Es decir, el $15 \%$ de la PEAR recibe el $5 \%$ de ingresos. A nivel microeconómico, esto representa US\$3.82 de salario diario o US\$687.60 en los seis meses de trabajo estimado. ${ }^{2}$ Esto necesariamente obliga a las personas a buscar un segundo trabajo, o a que varios miembros de las familias se involucren en actividades remuneradas. Dentro del ramo de agricultura, ganadería, caza y silvicultura, la masa salarial pagada en el subsector es del $54 \%$, es decir, el $57 \%$ de este ramo recibe el $54 \%$ de la masa salarial pagada. En ambas relaciones mencionadas estamos ante un cociente menor a uno.

\subsection{Cobertura del valor de la fuerza de trabajo}

Para los anteriores párrafos se analizó la masa de salarios nominales; sin embargo, como nos explican los teóricos clásicos, el dato relevante es la cantidad de 
bienes que este salario nominal permite alcanzar para procurar las necesidades de las familias. Haciendo referencia a la categorización marxista, se analiza el nivel de cobertura del valor de la fuerza de trabajo que los salarios nominales permiten. Para el valor de la fuerza de trabajo, se asume el precio de la Canasta Básica Rural (CBR).

El cuadro 1 muestra para el período 2001-2011 los salarios mínimos nominales fijados vía decreto en el Congreso del país, en su comparación con el costo de la CBR. De esta comparación se evidencia la insuficiencia del salario mínimo rural para cubrir el costo de la CBR que, se asume, permite la reproducción de la fuerza de trabajo, tomando en cuenta que estos salarios deben ser suficientes para mantener al trabajador como a su familia. ${ }^{3}$

La quinta columna de la tabla 1 refleja la proporción en que el salario nominal está por debajo del costo de la CBR, y por tanto lo que debería aumentar para poder cubrir el costo de una canasta; a medida se reduce este porcentaje, el salario mínimo se aproxima a garantizar la reproducción de la fuerza de trabajo, pero para ningún año del período en cuestión se logra cubrir la canasta alimentaria en su totalidad, lo que supone dificultades en la reproducción y cobertura de las necesidades más básicas de una familia que dependa del trabajo generado en la zona rural.

\section{Cuadro 1. Salario mínimo rural y canasta básica rural}

\begin{tabular}{|c|c|c|c|c|c|c|c|}
\hline \multirow{2}{*}{$\begin{array}{l}\text { Año } \\
2001\end{array}$} & \multirow{2}{*}{\multicolumn{2}{|c|}{$\begin{array}{l}\text { Salario mínimo rural } \\
\qquad \begin{array}{c} \\
\$ \quad 67.11\end{array}\end{array}$}} & \multicolumn{2}{|c|}{$\begin{array}{c}\text { Canasta Alimentaria } \\
\text { Rural }\end{array}$} & \multicolumn{2}{|c|}{ Diferencia } & \multirow{2}{*}{$\begin{array}{l}\begin{array}{c}\text { \% sobre } \\
\text { Salario } \\
\text { mínimo }\end{array} \\
44 \%\end{array}$} \\
\hline & & & $\$$ & 96.75 & $\$$ & (29.64) & \\
\hline 2002 & $\$$ & 67.12 & $\$$ & 92.88 & $\$$ & (25.76) & $38 \%$ \\
\hline 2003 & $\$$ & 67.13 & $\$$ & 89.80 & $\$$ & $(22.67)$ & $34 \%$ \\
\hline 2004 & $\$$ & 67.14 & $\$$ & 96.83 & $\$$ & (29.69) & $44 \%$ \\
\hline 2005 & $\$$ & 74.10 & $\$$ & 101.03 & $\$$ & $(26.93)$ & $36 \%$ \\
\hline 2006 & $\$$ & 81.60 & $\$$ & 99.18 & $\$$ & (17.58) & $22 \%$ \\
\hline 2007 & $\$$ & 85.80 & $\$$ & 110.78 & $\$$ & (24.98) & $29 \%$ \\
\hline 2008 & $\$$ & 90.00 & $\$$ & 127.87 & $\$$ & $37.87)$ & $42 \%$ \\
\hline 2009 & $\$$ & 97.20 & $\$$ & 120.91 & $\$$ & (23.71) & $24 \%$ \\
\hline 2010 & & 114.70 & $\$$ & 118.43 & $\$$ & (3.73) & $3 \%$ \\
\hline 2011 & $\$$ & 114.70 & $\$$ & 144.36 & $\$$ & (29.66) & $26 \%$ \\
\hline
\end{tabular}

Fuente: Elaboración propia con base en datos de la DIGESTYC. 
Entre 2001 al 2004, el promedio de no-cobertura del valor de la fuerza de trabajo fue del $40 \%$, es decir, que los asalariados deberán buscar otras vías de obtención de ingreso o asumir el desgaste progresivo. En los últimos tres años de análisis, el promedio de no-cobertura es del $18 \%$.

Por tanto, con base en los datos oficiales de las instituciones, se evidencia la incompleta cobertura del valor de la fuerza de trabajo por medio del salario mínimo rural, es decir, que este no es capaz, por sí solo, de sostener la vida de la persona que lo recibe. Esta relación salarial insuficiente, sin embargo, no es opcional del trabajador sino necesaria dado que el trabajador es el único medio que posee para hacer frente a sus necesidades propias y familiares de alimentación y subsistencia.

La profundidad del análisis, no obstante, debe trascender de una situación fáctica a la búsqueda de razones que expliquen la situación de la distribución del ingreso, siendo que éstas son en primera instancia la causa de las dificultades que atraviesa el asalariado caficultor. Recordando a Marx, pues, son las relaciones sociales de producción las que explican la dinámica de la distribución del ingreso y por tanto las que se analizan en los párrafos siguientes, iniciando con las relaciones sociales de producción que se establece entre los asalariados y los agentes que benefician y exportan el café.

\subsection{Tasa de explotación y sobrexplotación laboral}

La explotación se da cuando el capitalista se apropia del excedente que genera la fuerza del trabajo, mientras que el trabajador recibe en compensación su salario. Por lo tanto, los empleos generados por el sector cafetalero representan el número de relaciones de explotación que se dan.

En el presente apartado se realiza un análisis de la tasa de explotación del sector asalariado respecto a los ingresos generados por la producción de café. ${ }^{4}$ Para el análisis correspondiente se utiliza la estimación de la masa salarial proveniente de los ocupados en la producción de café; una segunda variable a ocupar es el valor de las exportaciones, que será tomado como el valor agregado generado por el sector, dado que el $90 \%$ de la producción de café es destinada a la exportación (BCR, 2012).

La gráfica 1 nos muestra para los años cosecha 1989/90-2011/12 la evolución del Excedente Bruto de Explotación (EBE) y la Masa Salarial (S) con respecto al Valor Agregado generado por el café (VA). ${ }^{5}$ De 1989 a 1996, se observa una disminución de la participación de los salarios dentro del VA en $21 \%$. Esta caída se debe a la transformación de colones 
a dólares ${ }^{6}$ de un salario mínimo que no varió en esos años entre una tasa de cambio en aumento. De 1996 a 2001 la participación de la fuerza de trabajo aumenta en un $31 \%$ debido a una caída de los precios promedios internacionales, cuyo impacto disminuye el producto relativo del cual se apropian los capitalistas y, por lo tanto, el cociente, sin obviar que la participación de la masa salarial también cayó pero en menor medida $y$, por tanto, aumenta su participación relativa en el total del producto. Sin embargo, cabe aclarar que durante este periodo se disminuyó la participación en el empleo en un 34\%, disminuyó la masa salarial en un $21 \%$ y el valor del producto exportado en un $79 \%$. Por tanto, el aumento de la participación de la masa salarial no significa una mejora en el nivel de ingreso absoluto de los asalariados.

\section{Gráfica 1}

\section{Evolución del EBE y la masa salarial 1989/90-2011/12}

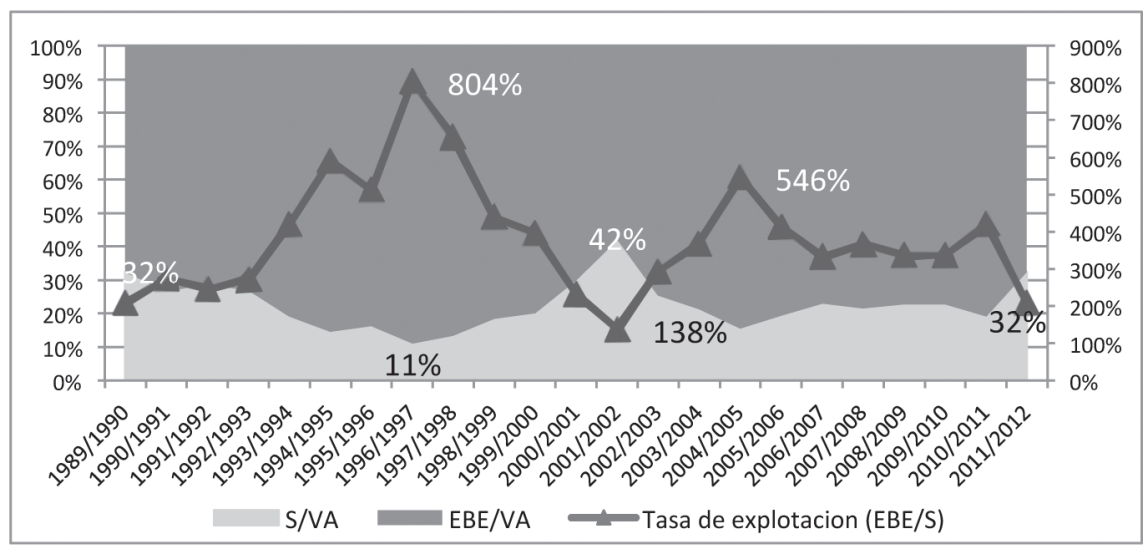

Fuente: Elaboración propia con base en datos de CSC y DIGESTYC.

En el periodo 2001-2011 la tasa de participación de la masa salarial en el producto total disminuye en un $10 \%$, esto debido al crecimiento del precio internacional en una mayor proporción que el crecimiento de los salarios. El crecimiento del salario mínimo de 2001 a 2011 es del $71 \%$, mientras que el incremento de los precios internacionales en los mismos años es del $314 \%$, es decir, parece ser que hay una relación directa entre el nivel del precio internacional y la brecha distributiva. Entonces, cuando se eleva el precio internacional, incrementa la brecha distributiva a favor de la clase capitalista. Esto es así porque los salarios pagados a los cortadores y demás asalariados se rigen fundamentalmente por los niveles de salario mínimo que son 
fijados vía decreto, mientras que el precio internacional se mueve constantemente. Entonces, aún y cuando el precio internacional puede subir a niveles extraordinarios, no hay ninguna obligación por parte del productor a remunerar a sus trabajadores en mayor cuantía y, por tanto, los precios internacionales extraordinariamente altos no benefician a los asalariados, siendo así que los precios internacionales en crecimiento pueden implicar tasas de explotación igualmente crecientes.

Un estimado de la tasa de explotación es un cociente entre el Excedente Bruto de Explotación y la masa salarial; hasta 1996, esta tasa aumentó $285 \%$ con respecto a 1989, Ilegando a tasa de explotación de $806 \%$. Esto significa que por cada dólar pagado al trabajador, la clase capitalista se apropia de ocho dólares. A partir de 1996, esta tasa cae a su punto más bajo $(138 \%)^{7}$ en el periodo de estudio en 2001. Esto puede ser explicado por la crisis de precios internacionales. Después de esta crisis, la tendencia de la tasa de explotación ha sido a "estabilizarse", logrando un promedio de $362 \%$ entre 2002-2011.

\subsection{Sobreexplotación laboral y la masa de plusvalía extraordinaria}

Como ya se dijo, la sobreexplotación es la remuneración sistemática de la fuerza de trabajo por debajo de su valor; así, la clase trabajadora se ve obligada a buscar su reproducción por vías no capitalistas, y estos últimos obtienen una porción adicional de ingresos (o de ahorro en $\operatorname{costos}^{8}$ ) que se le llama plusvalía extraordinaria. Nuestro análisis se basa en la diferencia entre el salario mínimo y el costo de la canasta básica rural; esta diferencia representa un estimado de la plusvalía extraordinaria de la cual se apropia el capitalista.

La gráfica 2 muestra la evolución de la Masa de Plusvalía Extraordinaria (MPVE) acumulada de 2001 a 2011. Esta masa de plusvalía resulta de la agregación de la plusvalía extraordinaria que se obtiene de la sobre-explotación de cada uno de los empleados del sub-sector cafetalero; la agregación de la Plusvalía Extraordinaria (PVE) se obtiene de la diferencia entre el salario mínimo rural y el precio de la CBR, multiplicado por el número de empleos involucrados. 
Gráfica 2.

Masa de plusvalía extraordinaria acumulada 2001-2011

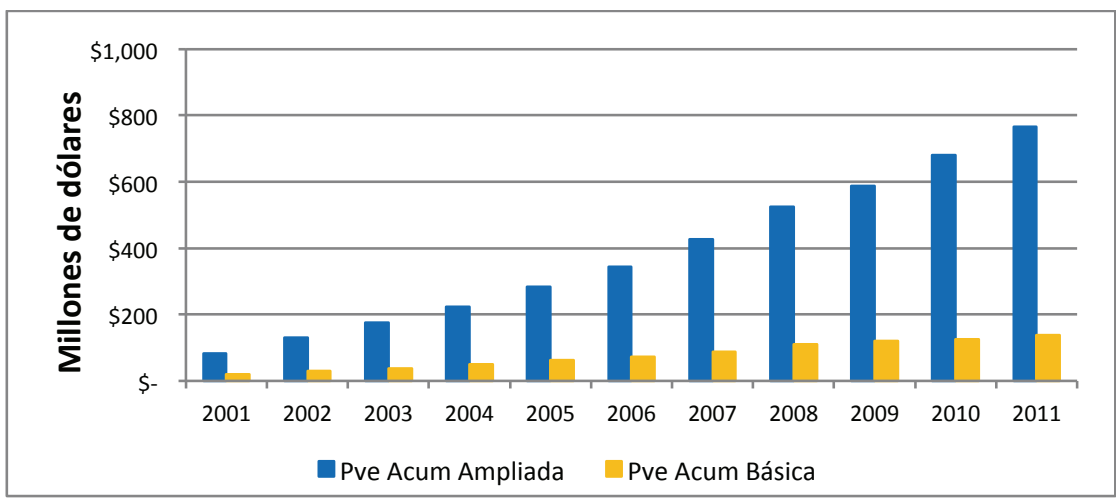

Fuente: Elaboración propia con base en datos de EHPM, DIGESTYC y CSC.

Para todos los años la tendencia de la plusvalía extraordinaria acumulada es creciente, lo que significa una remuneración sistemática de la fuerza de trabajo por debajo de su valor. Esta situación ha permitido, en suma, ingresos (valor no remunerado) a los capitalistas en el orden de los 138 millones de dólares. Esta suma de dinero hubiera llegado a manos de los asalariados si se les hubiera remunerado en la cuantía de su valor, pero dado que no ha sido así, han debido buscar de alguna manera trabajos adicionales que permitan ingresos adicionales o cultivos de subsistencia.

Si se toma un parámetro más alto para el valor de la fuerza de trabajo -el precio de la Canasta Rural Ampliada (CRA) en este casoy se procede a la agregación de plusvalía extraordinaria con base en este parámetro, tenemos una masa de plusvalía extraordinaria obviamente mayor, y un acumulado para el período que excede los 700 millones de dólares (ver gráfica 2). Lo relevante de esta aproximación es que parece que es el precio y los bienes de la canasta ampliada los que pueden en mayor medida satisfacer las necesidades más allá de la mera subsistencia de calorías que permite la canasta básica, y en ese sentido, si se toma esta canasta como parámetro mínimo para una subsistencia digna, entonces la plusvalía extraordinaria que se apropia el capitalista es mucho mayor.

\subsection{Depauperización de las condiciones de vida de la clase trabajadora}

Rosa Luxemburgo denomina depauperización relativa de la clase obrera $^{9}$ al fenómeno en que la masa de salarios tenderá a repartirse entre 
una masa cada vez mayor de proletarios, por lo que a cada trabajador le corresponderá una menor porción de la masa salarial a medida avanza el tiempo, dificultando sus condiciones de vida. Para el cálculo de este grado de depauperización se utilizará la siguiente fórmula presentada en Guerrero (2000):

$$
\mathrm{DR}=\frac{\frac{\mathrm{S}}{\mathrm{VA}}}{\frac{\text { Prol }}{\text { PEA }}}=\frac{\mathrm{SR}}{\text { GrProl }}
$$

En la gráfica 3, se muestra, para el periodo 2001-2011, el índice de depauperización de la clase trabajadora con base en sus determinantes: los salarios relativos con respecto al valor agregado y el grado de proletarización del sector.

\section{Gráfica 3}

\section{Evolución de la depauperización de la clase trabajadora y sus determinantes}

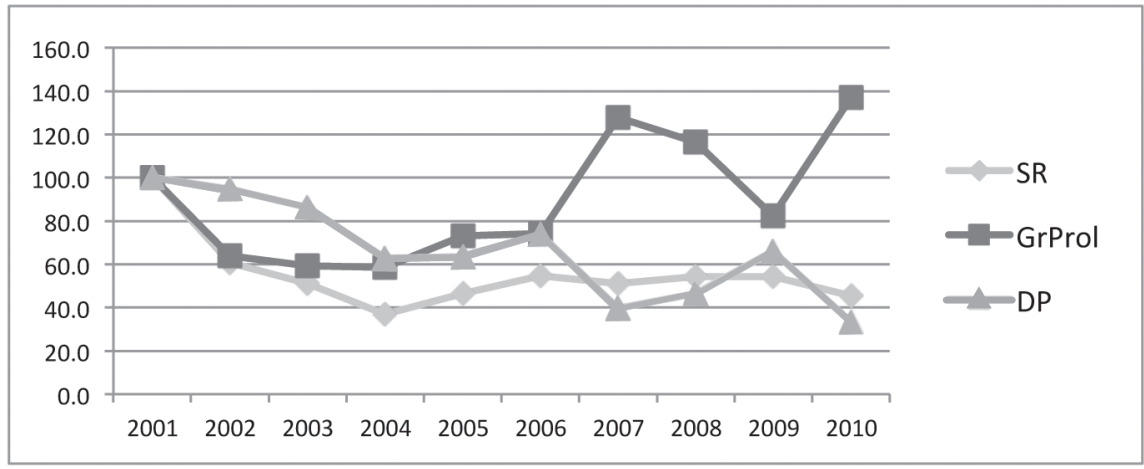

Fuente: Elaboración propia con base en datos de DIGESTYC, EHPM y CSC.

La tendencia negativa del índice de depauperización (DP) revela un mayor grado de desigualdad distributiva de la clase trabajadora del café con respecto a la clase capitalista, y para los años en estudio la depauperización relativa se ha incrementado en un $67 \%$ al 2011 con respecto al año base. El grado de proletarización indica que si bien los primeros años cae por debajo del año base -debido principalmente al menor uso de mano de obra en los años de la crisis de los precios del café-, en los últimos cuatro años su comportamiento ha sido a incrementar en un promedio de $15.9 \%$ por encima de lo indicado en 2001; por otra parte, los salarios relativos muestran un desplome del $50 \%$ en promedio para el periodo 2001-2011. En resumen, a una cantidad creciente de proletarios, le corresponde una masa que crece en menor cuantía de salarios relativos.

Así pues, tenemos hasta este momento demostradas tres situa- 
ciones que se dan en los asalariados del café: la primera, que los asalariados no reciben salarios que cubran el valor de su fuerza de trabajo; la segunda, que los asalariados son sobre-explotados debido a una remuneración sistemática de la fuerza de trabajo por debajo de su valor. Ambos factores contribuyen a la tercera situación: la depauperización progresiva de la clase obrera.

\section{Pequeño productor}

A medida se analizan las formas de distribución dentro de la dinámica de producción de café en El Salvador, las teorías de Carlos Marx en torno al análisis del capitalismo, así como las formas inherentes en que el sistema explota y se apropia del valor generado por la clase trabajadora, parece describir a la perfección las desigualdades existentes y la disparidad distributiva de la riqueza generada.

El sistema capitalista presupone entonces la separación completa de los trabajadores de toda propiedad de medios de producción, transformándolos en trabajadores asalariados y/o subsumiéndolos de forma directa en el capital. La producción de café en El Salvador desde sus inicios ilustra la validez de esta teoría respecto al origen de la producción capitalista, así como la desigualdad que genera, persiste y/o se amplían en los periodos actuales.

Para el presente estudio se ha considerado relevante el análisis de la distribución de la tierra. Como se evidenciará a continuación, la concentración de la tierra en el subsector es evidente $y$, por tanto, se alinea en la histórica, persistente y sistemática problemática de desigual distribución de la riqueza y medios de producción.

\subsection{Concentración de la tierra}

La concentración capitalista, propuesta por Marx, puede ser reflejada mediante la concentración de los medios de producción. Para este estudio se utilizará un factor determinante que describe esta teoría: la tenencia de la tierra. La gráfica 4 muestra la curva de Lorenz trazada según los datos registrados por el Consejo Salvadoreño de Café a 2010, con base en los datos levantados en el Censo Nacional Agropecuario 2007. Se demuestra una distribución inequitativa en la tenencia de tierra, geométricamente expresada por su forma exponencial. Los pequeños productores, ${ }^{10}$ grupo objetivo de análisis para el estudio, poseen el $81 \%$ del número total de fincas, que equivale al $19 \%$ del total de la tierra. ${ }^{11}$ 
Gráfica 4

Curva de Lorenz para la distribución de la tierra, 2007/08

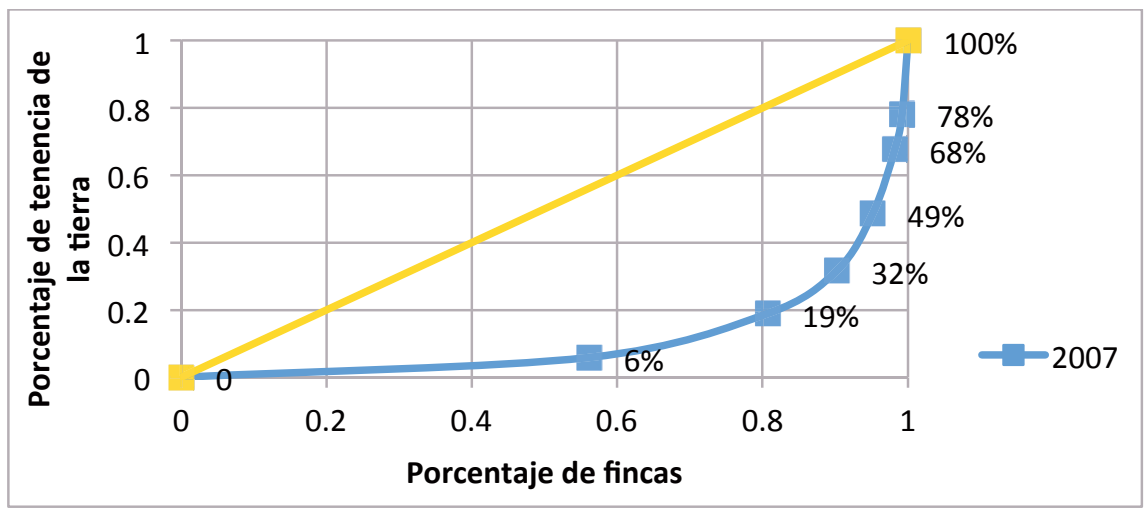

Fuente: Elaboración propia con base en datos del IV Censo Agropecuario (CENAGRO 2007).

Por tanto, para demostrar la concentración de la tenencia de la tierra se ha calculado que el $19 \%$ de las fincas de café agrupan el $81 \%$ restante del total de área cultivada, confirmando la inequidad en la distribución de la tierra para el cultivo de café. Es evidente que existe un estrato reducido de productores que poseen la mayor cantidad del medio de producción más importante, que los convierte en la clase dominante dentro de la dinámica productiva del subsector cafetalero. Para expresar la situación de la distribución en un indicador, se ha recurrido al índice de Gini. ${ }^{12}$ Siguiendo la metodología de Lazo (2010), el resultado para el año en estudio es:

$$
C G=0.623
$$

Un coeficiente por arriba del 0.60 representa una distribución muy desigual, es decir, para El Salvador se tiene un alto grado de desigualdad en la tenencia de la tierra cultivada para café, tal como ya se demostraba en la curva de Lorenz. Así pues, nos encontramos ante una situación en que los medios de producción están concentrados en pocas manos, lo que con toda lógica conduciría a una situación en la que el ingreso generado por la actividad económica que utiliza esos medios de producción esté también concentrado en pocas manos.

Podemos ahondar aún más en nuestro análisis utilizando el rendimiento por manzana y el precio promedio pagado al productor, con lo que obtenemos el ingreso promedio. Los pequeños productores producen el $23 \%$ del ingreso generado por los grandes productores, a pesar de que la relación existente entre las dos clases sea de veinte peque- 
ños productores por cada gran productor; es decir, por cada productor mediano y grande de café, arriba de 10 manzanas, existen al menos veinte pequeños productores con plantaciones de hasta 10 manzanas.

De esta concentración se desprende consecuentemente un alto grado de concentración de los ingresos. Estas dos situaciones de concentración son el punto de partida que dan pie a una tendencia que es universal en el modo de producción capitalista: el acaparamiento de los medios de producción y las facilidades para crecer y concentrar aún mayores cuantías de riqueza. Son los poseedores de la tierra y de las grandes producciones los que finalmente lograrán mayor producción, obtendrán créditos más fácilmente, mejorarán la productividad, capacitarán a empleados administrativos, etc., que les permitirá aumentar aún más la concentración del ingreso y medios de producción.

Como hemos visto, dentro del sector cafetalero existe concentración del medio de producción más importante de todos; y los pequeños productores, a pesar de ser muchos, no son capaces de acceder a los beneficios que acarrea la dinámica de producción y comercialización del café. Sin embargo, cumplen una parte importante en la valorización de los capitales como subsumidos indirectamente dentro de ellos.

\subsection{Subsunción indirecta del trabajo en el capital}

La masa de personas que no trabajan bajo relación salarial en el sistema capitalista -pero que contribuyen a valorizar el capital con su trabajo sin que exista una relación salarial mediadora- son subsumidos indirectamente en el capital: los pequeños productores, por tanto, están subsumidos indirectamente en el capital. Esto es así, dado que son los pequeños productores aquéllos cuya capacidad no les permite Ilegar más allá de la etapa de producción a pequeña escala, y entonces se ven obligados, necesariamente, a encaminar su café hacia el proceso agroindustrial del beneficiado, sin que este último actor asuma ningún riesgo intrínseco de la producción del café y así valoriza el capital.

Siguiendo los diferenciales entre el precio de venta del café respecto al precio pagado al productor, y agregando el producto generado solamente por los pequeños caficultores, se obtiene la situación en la distribución del ingreso generado para el período 1997-2010. ${ }^{13}$ El excedente bruto de explotación, es decir, la masa del ingreso que se apropia el beneficio-exportador para los trece años en cuestión, promedia el $44 \%$ del valor agregado, mientras que para la masa de ingreso al productor se tiene un promedio del 56\%. Hasta aquí el análisis, 
parece que proporcionalmente son los pequeños productores los que reciben los mayores frutos del COmercio de su café.

Si se analiza la evolución de las proporciones de la gráfica 5 con respecto a la coyuntura internacional de los precios, muestra que en el proceso de apropiación del ingreso son los beneficio-exportadores los actores que finalmente se ven menos afectados en tiempos de crisis y más beneficiados en tiempos de bonanza: para la crisis de 2001, el peso relativo del excedente bruto de explotación incrementa, mientras que para los tiempos en que los precios internacionales fueron presentando tendencias incrementales positivas, el peso relativo que aumenta es el de la Masa de Ingreso de los Productores (MIP). No obstante, aun cuando los precios internacionales muestran alza en los últimos años del gráfico, el peso de la MIP se estaciona. Es decir, parece ser que las situaciones de extrema bonanza de los precios únicamente generan mejores ingresos al actor beneficioexportador que parece controlar a su antojo los precios que paga al productor.

Gráfica 5

\section{Apropiación del ingreso generado por pequeños productores, 1997-2010}

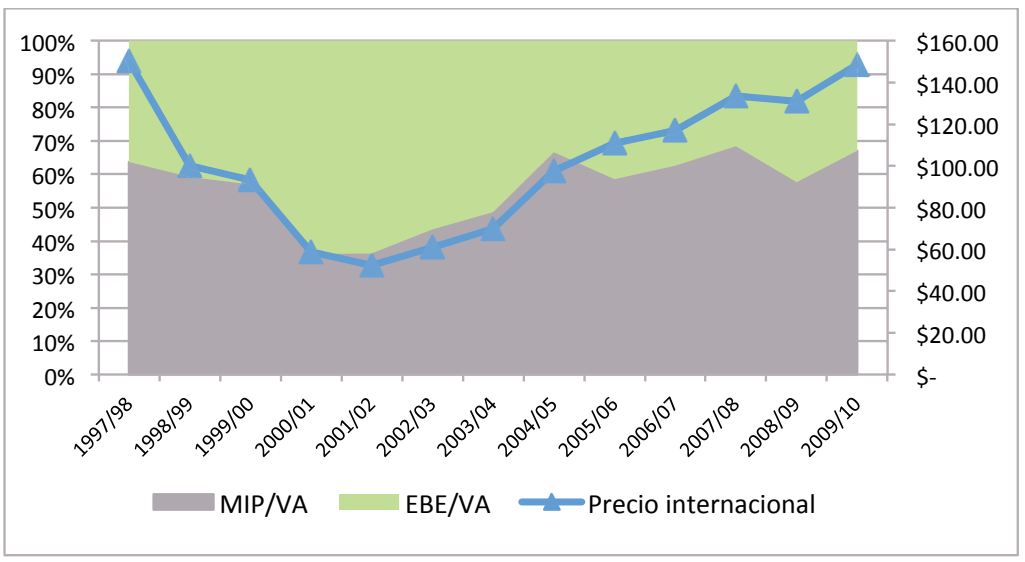

Fuente: Elaboración propia con base en datos del CSC, PROCAFÉ

La brecha que se abre en la apropiación del ingreso, en momentos de mejores precios internacionales, es un hecho con una lógica de fácil comprensión si se hace alusión al bajo poder de negociación que tienen los pequeños productores. $\mathrm{Si}$ se analiza la porción del café que éstos producen respecto a la producción total, poco podrán hacer para influir en el precio de compra que les ofrece el beneficio-exporta- 
dor. La gráfica 6 muestra la evolución de la porción de producción que los pequeños aportan al total, siendo demasiado baja como para darles margen de negociación sus- tancial en el precio recibido por sus quintales; además, si no venden su café, se acortan las opciones para la subsistencia del pequeño productor y la familia que debe mantener.

\section{Gráfica 6}

\section{Evolución de la porción de producción de los productores con fincas de hasta 10 manzanas de café, respecto al total de café producido}

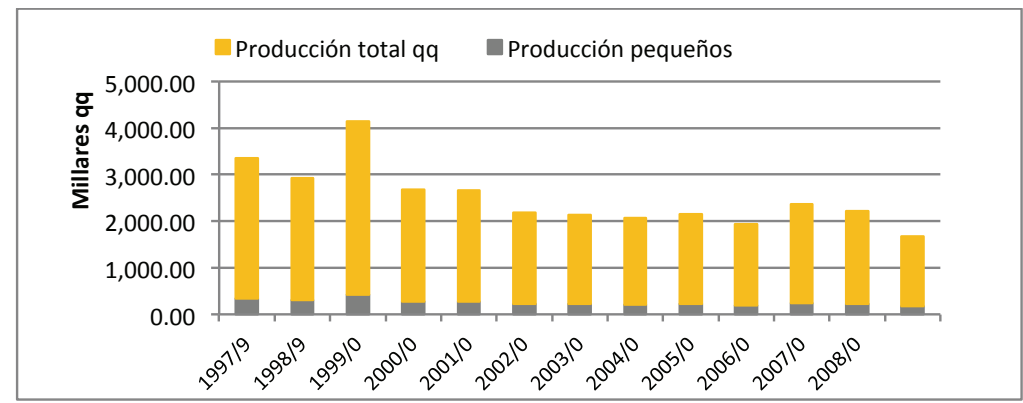

Fuente: Elaboración propia con base en datos de CSC y PROCAFÉ.

Ahora bien, si se vuelve a ver la gráfica 5, la porción que le corresponde a los pequeños productores del ingreso que se genera de su producción de café, no es nada despreciable, aunque sí es relativamente baja en comparación al demás producto, que es generado por todas aquellas fincas de más de 10 manzanas y que concentran el $81 \%$ de la tierra; sin embargo, una conclusión de este tipo y un análisis hasta este punto puede resultar engañoso, y hacer creer que la situación del pequeño caficultor es aceptable. Sin embargo, al trascender en el análisis, es necesario verificar qué porción de este ingreso es utilizado para cubrir los costos mismos de la producción del café, y qué porción es ganancia para el productor y su familia.
En la gráfica 7 se muestra la evolución de la Masa del Ingreso al Productor en comparación con la masa de costos de producción del café para los años entre 1997 y 2010. Como es notorio, los costos son menores en la mayoría de los años al ingreso, y para los años en análisis, por cada dólar en ingreso, setenta y tres centavos en promedio corresponden a los costos de producción de su café. En el período de crisis, y dos años inmediatamente posteriores, los costos de producción superan a los ingresos, siendo estos años especialmente difíciles para los pequeños productores y cuyas secuelas en endeudamiento se mantienen aún en la actualidad para gran parte del sector cafetalero. Sin olvidar que los capitalistas 
también consideran a los salarios como un costo de producción, vale la aclaración de que por estar exa- minando los costos de un pequeño productor no se toman en cuenta pagos de salarios.

\section{Gráfica 7}

\section{Evolución comparativa entre la masa de ingreso al pequeño productor y sus costos de producción, 1997-2010}

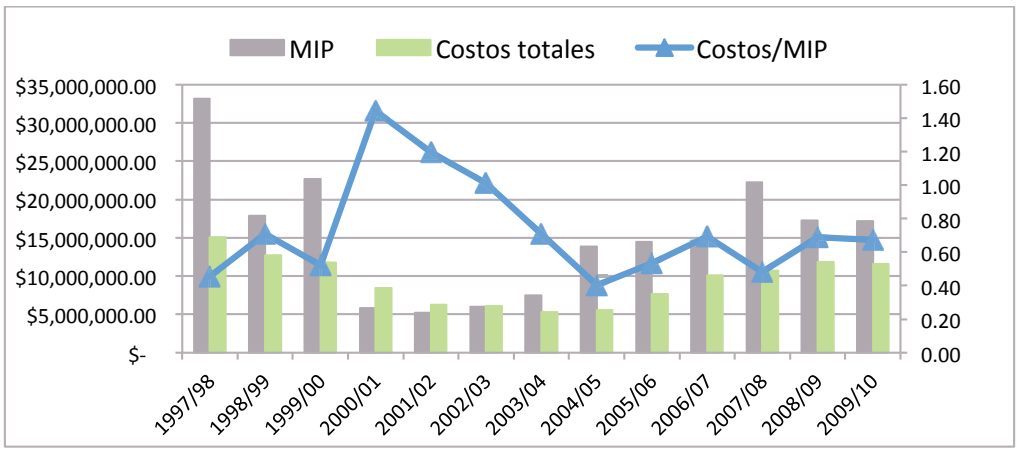

Fuente: Elaboración propia con base en datos de CSC, EHPM, y PROCAFÉ

Es muy importante mencionar que, para efectos del análisis, este costo de producción no reúne todos los centros de costo que agrupa el costo total de producción que señala PROCAFÉ (2010). Según la información proporcionada por el pequeño productor Carlos Rivera, ${ }^{14}$ los ingresos que les deja el café en los ejercicios anteriores y la disponibilidad de flujo para hacer frente a todos los costos de la vigente producción no les permite realizar todas las prácticas agrícolas necesarias para un buen cuido del cafetal, además que para los productores de hasta 10 manzanas no se ha hecho cuenta de desembolsos en concepto de salario y mano de obra, por ser una porción de tierra cuyas actividades cafetaleras pueden ser cubiertas con mano de obra propia o familiar, que ya habíamos dicho era el aspecto clave que les convertía en subsumidos indirectamente en el capital.

Los costos de producción del gráfico 7 , por falta de información estadística para cada año, se han construido con base en la proporción que cada centro de costo representa del costo total para la cosecha 2009/2010 (ver cuadro 2). Pero, como se menciona en el párrafo anterior, para el costo por manzana de las explotaciones entre cero y diez manzanas, no se toman en cuenta ciertos costos del promedio nacional. ${ }^{15}$ Las explotaciones de cero a tres manzanas presentan un costo promedio de US\$74.12/Mz.; y para las explotaciones entre tres $y$ diez manzanas, el promedio se eleva a US\$286.60/Mz. 
Cuadro 2

Costo promedio de producción por manzana de café, nivel nacional y por altura (2010)

\begin{tabular}{|l|c|c|c|c|}
\hline \multicolumn{1}{|c|}{ COMPONENTES DEL COSTO } & $\begin{array}{c}\text { Nacional } \\
\text { (Dólares/mz.) }\end{array}$ & $\begin{array}{c}\text { Estricta altura } \\
\text { (Dólares/mz) }\end{array}$ & $\begin{array}{c}\text { Media altura } \\
\text { (Dólares/mz.) }\end{array}$ & $\begin{array}{c}\text { Bají } \\
\text { (Dólares/mz.) }\end{array}$ \\
\hline COSTOS DIRECTOS & $\mathbf{6 8 2 . 5}$ & $\mathbf{6 5 5 . 6}$ & $\mathbf{5 3 0 . 4}$ & $\mathbf{4 5 6 . 2}$ \\
\hline Insumos & 272.1 & 237 & 220 & 148.7 \\
\hline Mano de obra & 165.7 & 102.8 & 117.7 & 115 \\
\hline Recolección & 222.1 & 303.8 & 179.4 & 158.2 \\
\hline Transporte & 22.6 & 12 & 13.3 & 34.4 \\
\hline COSTOS INDIRECTOS & $\mathbf{9 2 . 6}$ & $\mathbf{1 0 4 . 4}$ & $\mathbf{8 7 . 8}$ & $\mathbf{8 2 . 4}$ \\
\hline Administración & 92.6 & 104.4 & 87.8 & 82.4 \\
\hline SUBTOTAL & $\mathbf{7 7 5 . 1}$ & $\mathbf{7 6 0}$ & $\mathbf{6 1 8 . 2}$ & $\mathbf{5 3 8 . 7}$ \\
\hline Gastos financieros (i. a. de 9.32\%) & 72.2 & 70.8 & 57.6 & 50.2 \\
\hline TOTAL & $\mathbf{8 4 7 . 3}$ & $\mathbf{8 3 0 . 8}$ & $\mathbf{6 7 5 . 8}$ & $\mathbf{5 8 8 . 9}$ \\
\hline
\end{tabular}

Fuente: Tomado del boletín estadístico de PROCAFÉ, 2010.

Retomando la situación de la porción del ingreso que reciben los pequeños productores (ver gráfica 7), éste es relativamente elevado; pero una vez se le analiza en conjunto a los costos que permiten esos ingresos, el margen de ganancia para los pequeños productores es bastante limitado; además, si a esto se le añade que no se está tomando en cuenta todos los centros de costo para mantener un cafetal sano y en óptimas condiciones productivas para los siguientes ejercicios, estamos pues ante una progresiva situación de deterioro de los cafetales de los pequeños productores que, sin embargo, no por esto dejan de contribuir a la acumulación de capital de los beneficio-exportadores con sus precios de venta bajos. Además, se abre pie a una mayor concentración de la tierra, si estos productores no son capaces de saldar la deuda que pudiesen necesitar para producir, crédito muchas veces facilitado por los mismos beneficios, o la deuda que ya arrastran de los rescates al subsector que se dieron a inicios de la década pasada.

Una categoría marxista importante es la expoliación que se da de los capitalistas a formas de producción subsumidas indirectamente en él. Así, de la estadística base para la gráfica 6 , se construye la gráfica 8 que muestra la evolución de la tasa de expoliación que se da entre los beneficios-exportadores y los pequeños productores. La tasa de expoliación ${ }^{16}$ para el período presenta un promedio simple de 0.88 para este período en análisis. Esto quiere 
decir que de cada dólar de ingreso para los pequeños productores, se generaron ochenta y ocho centavos de excedente bruto de explotación para los beneficios-exportadores. Sin acotar el análisis únicamente al promedio, para el tiempo de crisis se tiene la más alta tasa de expoliación (de 1.78), siendo que por cada dólar de ingreso para los productores, los beneficios lograron un excedente bruto de explotación de US\$1.78. Este último dato es sumamente importante, dado que se estaría ante un escenario en donde las caídas eventuales de los precios internacionales impactan más al pequeño productor, cuya pérdida sirve como amortiguador de la pérdida potencial de los beneficios.

\section{Gráfica 8}

\section{Evolución de la tasa de expoliación de los beneficios-exportadores a los pequeños productores, período 1997-2010}

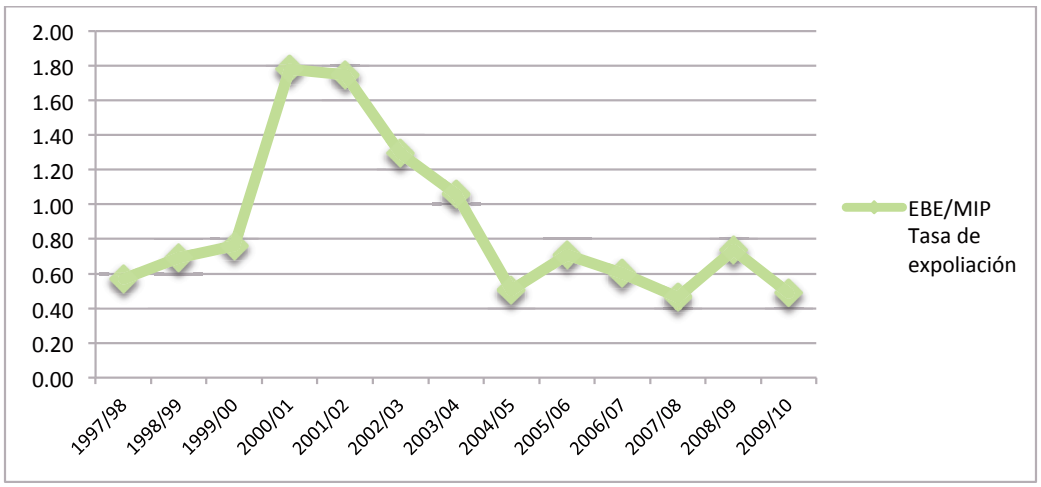

Fuente: Elaboración propia con base en datos de CSC y PROCAFÉ

\section{Conclusiones}

La hipótesis que se buscaba comprobar sostenía que la naturaleza de la dinámica de producción y comercialización de café, y la lógica que se ha venido consolidando luego de más de un siglo de operar a nivel nacional, ha generado un empobrecimiento paulatino de las condiciones de vida de los actores más vulnerables de la cadena productiva (los asalariados y los pequeños productores), estableciéndose y exacerbándose la desigualdad en la distribución del ingreso generado. Dicha hipótesis ha sido comprobada luego de los esfuerzos empíricos realizados, resultados que se resumen en los siguientes puntos.

La tenencia de la tierra ha sido fundamental en la estructura productiva y comercializadora histórica del café. El poder que acumularon ciertos grupos a finales del siglo XIX e inicios del XX ha determinado a los actores de la cadena producti- 
va. Dentro de los actores, son los beneficiadores-exportadores los herederos de aquellas estructuras de poder y los que actualmente dominan e imponen su hegemonía sobre los eslabones inferiores.

Los beneficiadores-exportadores operan bajo la lógica de acumulación de capital, y bajo su lógica se desenvuelven los asalariados y pequeños productores que se ven obligados indefectiblemente a vender su fuerza de trabajo o su producción para hacer frente al problema fundamental de la reproducción de sus familias. En ese sentido, aparecen de la lógica capitalista y su objetivación en la realidad cafetalera, expresada en los beneficiadores-exportadores las categorías marxistas: cobertura del valor de la fuerza de trabajo, explotación, sobreexplotación, subsunción directa e indirecta del trabajo en el capital, y expoliación.

Los asalariados del sector cafetalero enfrentan el problema de su reproducción, desde un inicio, con salarios mínimos rurales, fijados oficialmente, que no cubren los costos de la canasta básica rural y mucho menos la canasta rural ampliada. En ese sentido, la nocobertura del valor de su fuerza de trabajo y la de su familia está validada desde instancias gubernamentales.

Los bajos niveles de salarios del subsector cafetalero han per- mitido altas tasa de explotación en el subsector $y$, por tanto, altas tasas de valorización del capital. Por cada dólar de salario pagado a los empleados, el beneficio-exportador registra ingresos por ocho dólares. Esta situación exacerba la brecha de desigualdad que históricamente ha presentado el subsector entre los actores y pauperiza las condiciones de vida de la clase trabajadora.

Los salarios por debajo del valor de la fuerza de trabajo han generado, para el capitalista, una masa de plusvalía extraordinaria creciente para todos los años en estudio, como producto de la sobreexplotación del asalariado. EI hecho de que sistemáticamente se paga el valor de la fuerza de trabajo, representado por el costo de la canasta básica alimentaria, genera una apropiación extra para el capitalista que le permite aún mayor valorización del capital.

Se muestra la desigual distribución de la tierra al analizar la situación de la tenencia de ésta en los pequeños productores y la cantidad de fincas que se tienen. El $81 \%$ del total de fincas que se halla para la producción de café solo agrupan el $19 \%$ de la tierra existente. Esto quiere decir que la situación histórica de la concentración de tierras en manos de grandes fincas y pocos productores se mantiene, lo que condiciona la vida de todas las personas que dependen de todos estos minifundios atomizados. 
Los pequeños productores y su baja producción individual como global los obliga a entregar su producción de café a los beneficiadores-exportadores. Estos suelen imponer sus condiciones de compra con base en precios internacionales que pueden o no estar en concordancia con las dificultades de producción y costos que el pequeño productor asume. Es por esto que el pequeño productor está subsumido indirectamente en el capital y, por tanto, contribuye a la valorización del capital.

En el período en análisis, son los beneficiadores-exportadores los que se apropian la mayor parte de los ingresos que se generan en la comercialización del café, a tal punto que no importa la situación económica en la que éste se encuentre, puesto que dentro de periodos de crisis aumentan las tasas de sobre-explotación y expoliación, en comparación con las tasas regulares en períodos de bonanza económica. Los afluentes de estos ingresos, no solo la comercialización sino ingresos "indirectos" por remuneraciones debajo del valor de la fuerza de trabajo que emplean, generan plusvalía extraordinaria y la expoliación a los pequeños productores.

Fruto de lo anterior, estos actores del eslabón de comercialización logran afrontar de mejor manera los tiempos de crisis de precios. Ante bajos precios, estos ingresos "indirectos" amortiguan la caída de los precios internacionales y sus márgenes de ganancia. Es decir, la explotación, sobre explotación y expoliación a los asalariados y pequeños productores, respectivamente, permite la subsistencia de los beneficiadores-exportadores en tiempos de crisis de precios bajos, a la espera de mejores precios que, cuando ocurren, les beneficia más a ellos que a los actores más retrasados en la cadena.

El café es un producto generador de divisas para el país y el mayor producto de exportación agrícola de El Salvador. Como tal, sin embargo, no ha significado bonanza en todos los actores involucrados en su producción y comercialización, sino que los ingresos generados van en su gran mayoría al eslabón final de comercialización, con el actor beneficiador-exportador, significando un sostenimiento o ampliación de la brecha distributiva en los actores que participan en la cadena.

Ha quedado evidenciado, entonces, cómo la dinámica de producción y comercialización ha significado y significa la pauperización de las condiciones de vida de los asalariados y pequeños productores de café. Es el Estado, pues, el que debe retomar su papel determinante mediante las políticas económicas que permitan generar condiciones para una distribución del ingreso de carácter justa, que reduzca las brechas de desigualdad y 
que dé apertura a nuevas formas de producción y asociación entre los eslabones más débiles de la cadena productiva del café.

\section{Recomendaciones}

En virtud de la situación descrita a lo largo de la presente investigación, las acciones de política económica se convierten en un aspecto clave a fin de cambiar esta situación de creciente desigualdad y pauperización. Sería ingenuo pensar que se puede desbaratar de tajo toda una estructura económica de más de cien años, mas sí nos parece posible que se pueden dirigir acciones para generar dinámicas de distribución y redistribución del ingreso que permitan cerrar paulatinamente, en algún grado, las amplias brechas de desigualdad existentes.

En el eslabón que acoge a los asalariados se hace necesario una revisión exhaustiva y constante de los salarios que se le pagan al trabajador por vender su fuerza de trabajo a los productores; en este análisis, deben primar aspectos que trasciendan la esfera puramente monetaria y tomar en cuenta aspectos como el derecho de la persona humana a disfrutar de una vida digna, y de asegurar la reproducción de la vida de las generaciones futuras no bajo condiciones de supervivencia sino de condiciones edificantes y dignificantes.

En cuanto a los pequeños productores, el principal obstáculo que encuentran para obtener mejores precios que permitan mejores condiciones de vida es su estructura desorganizada y la primacía del individualismo. Deberá fomentarse, como política de país, el incentivo de las formaciones productivas cooperativas y/o de producción comunitaria que permitan robustecer a los productores individuales con pequeñas fincas de café para trascender de su rol pasivo precioaceptante a un rol activo con cierta fuerza precio-determinante frente a los beneficios-exportadores. El fomento de la confianza y solidaridad como valores de estas estructuras deberá ser fundamental.

Por el lado de los beneficiosexportadores, las acciones de política no se circunscriben solamente al ámbito económico. Es necesario transparentar el ejercicio de estas unidades productivas, sobre todo en su interacción con los eslabones inferiores de la cadena y evaluar la creación de leyes, códigos o reglamentos para regir en mayor grado esta actividad, las decisiones que se toman y las consecuencias y frutos que se generan.

La creación de un sistema accesible de información para los pequeños productores de café es también una acción de política que coadyuvaría a robustecer la posición de los pequeños frente a los beneficios-exportadores. El mero hecho de que los productores conocieran los precios internacionales 
del café de manera inmediata les daría insumos para demandar mejores precios pagados al productor.

Así pues, atender a la demanda de los subsectores vulnerables no se trata de proponer proyectos que ayuden a generar una mayor cantidad de riqueza, sino de construir mecanismos en la distribución del ingreso generado y buscar la complementariedad entre las políticas y los actores para lograr la instauración de estrategias de orden integral.
Por eso, nuestro trabajo apunta al desarrollo de políticas que empiecen a apostar por las estrategias de desarrollo territorial protagonizadas por las comunidades organizadas, asocios de productores, movimientos cooperativistas, etc., de manera que las condiciones de vida de la mayoría vayan de acuerdo a la cantidad de riqueza generada por su trabajo y se generen ambientes solidarios de producción, reproducción y convivencia.

\section{Bibliografía}

os Álvarez, M. (2005) Orientaciones generales para la promoción y apoyo de las cadenas agroproductivas en el Perú. No definido. Lima. MINAG

os Banco Mundial (2004) Centroamérica la crisis cafetalera: efectos y estrategias para hacerle frente. Disponible en: http://siteresources.worldbank. org/LACEXT/Resources/258553-1123185549489/CA_La_Crisis_Cafe_ COMPLETO.pdf

os Beckerman, M. (2001) Encadenamientos productivos: Estilización de impactos sobre el desarrollo de los países periféricos. No definido. Buenos Aires. CATAIFE.

os Boyce, J., 1999. Ajuste hacia la Paz. La política económica y la reconstrucción de posguerra en El Salvador. México: Plaza y Valdez EditoresPNUD.

os Cartelier, J., (1981) Excedente y reproducción: la formación de la economía política y clásica, México D.F.: Fondo de Cultura Económica.

os CONFRAS (1999), Análisis de las cooperativas de producción agropecuaria, San Salvador, noviembre de 1999.

Disponible en: http://confras.com/documentos_b/Estudios/CONFRAS\%20-\%20Analisis\%20de $\% 20$ las $\% 2$ Cooperativas $\% 20$ de $\% 20$ Produccion\%20Agropecuaria\%201999.pdf

os CSC (2012) El Cultivo del Café en El Salvador 2012. El Salvador. 
os FAO (2011) Documento técnico 5. La incorporación de la Agricultura Familiar en las Cadenas de Valor. No definido. San Salvador. GCP/ ELS/008/SPA

os Banco Centroamericano de Integración Económica (2009) Inventario de las cooperativas productivas en El Salvador. San Salvador: Consorcio Etimos S.C.

os FONTAGRO y CATIE (2000) Caracterización de la agrocadena de café. Nicaragua, Proyecto Agrosilvopastoril.

os FUNDE (2010) Tenencia de la tierra y democratización de la propiedad en El Salvador, San Salvador. Disponible en: http://www.repo.funde. org/62/1/LIBROS-56.pdf

os FUNDE (2003) El impacto de la crisis del café en El Salvador, San Salvador. Disponible en: Goitia (1991), Reforma agraria con orientación de mercado, Revista Realidad, № 22. Disponible en: http://www.uca.edu. sv/revistarealidad/archivo/4e6a3d2558d9escan0255000.pdf

os Galdámez y Goitia (1993) "El movimiento campesino en El Salvador: evolución y lucha", Revista Realidad, № 36, San Salvador, disponible en: http://www.uca.edu.sv/revistarealidad/archivo/4e2da268729d3elmo vimientocampesino.pdf

os García, E., Grande, A., Morales, R. (2011) Impacto de la apertura comercial en la competitividad internacional y la distribución del ingreso en El Salvador: 1990-2010. Tesis de licenciatura. Antiguo Cuscatlán, Departamento de Economía, Universidad Centroamericana "José Simeón Cañas".

os Harris, D. (1986) Acumulación de capital y distribución del ingreso. Primera edición. México, Fondo de Cultura Económica.

os Hernández, G. (2012) "Caída de precios del café afecta a los productores", en elsalvador.com. 13 de Marzo de 2012. Disponible en línea en elsalvador.com.

os Hernández, G. (2012) "El Salvador, entre los 10 mejores cafés del mundo", en elsalvador.com. 13 de Marzo de 2012. Disponible en línea en elsalvador.com.

os Humphrey, J. (2006) Global Value Chains in the Agrifood Sector. No definido. Austria. UNIDO, Strategic research and economics branch.

os IHCAFE (2004) Requisitos de calidad del café para su comercialización nacional e internacional. Honduras. 
os ISAZA, No definido. Cadenas Productivas. Enfoques y precisiones conceptuales. Colombia: s.n.

os Instituto del Café de Costa Rica (ICAFE) 2005. Informe sobre la actividad cafetalera de Costa Rica. San José: s.n.

os Lazo, F. (2010) Clases Magistrales de Cuentas Nacionales. Universidad Centroamericana "José Simeón Cañas".

os Martínez, J y Acevedo, X. (2005) La cadena del café en Colombia. Una mirada Global de su estructura y dinámica 1991-2005. Documento de trabajo No. 59. Bogotá. Ministerio de Agricultura y Desarrollo RuralObservatorio Agrocadenas Colombia.

os Martínez, J. (2010) Clases Magistrales de Historia del Análisis Económico. Universidad Centroamericana "José Simeón Cañas".

os Martínez, J. (2011) Clases magistrales de Historia del Análisis económico I, Universidad Centroamericana "José Simeón Cañas".

os Marx, K. (1894) El Capital, Tomo III. Documento en línea: http://www. ucm.es/info/bas/es/marx-eng/capital3/

os Marx, K. (1977) El Capital, Tomo I. Quinta edición. México, Siglo veintiuno.

os Marx, K. (1979) Contribución a la crítica de la economía política. 9. Reimpresión. México. Ediciones de Cultura Popular.

os Ministerio de Agricultura y Ganadería, (2011a) Propuesta de políticas y procedimientos para la realización de los desembolsos de apoyos, incentivos y beneficios a los productores de café. "Rescate y Desarrollo de la Caficultura Nacional", El Salvador.

os Ministerio de Agricultura y Ganadería, (2011a) Plan de Agricultura Familiar y Empendedurismo Rural para la Seguridad Alimentaria y Nutricional, El Salvador: s.n.

os Montoya, A. (1980) Elementos introductorios al estudio de la sobreexplotación de la fuerza de trabajo y algunas consideraciones acerca del fenómeno del agro salvadoreño. Tesis de licenciatura. Antiguo Cuscatlán, Departamento de Economía, Universidad Centroamericana "José Simeón Cañas".

os Montoya, A. (1998) Economía Crítica. No definido. San Salvador, Editores críticos.

os Montoya, A. (2008) Clases Magistrales de Economía Crítica. Universidad Centroamericana "José Simeón Cañas". 
os PROCAFÉ (2011) Costos de Producción de Café en fincas cafetaleras de El Salvador 2010/11. Edición de Fundación Salvadoreña para Investigaciones del Café, La Libertad. Oficina central de fundación PROCAFÉ.

os PROCAFÉ, (2011) Competitividad: producir más café al más bajo costo. Hoja técnica. El Salvador. Edición de Fundación Salvadoreña para Investigaciones del Café, La Libertad. Oficina central de fundación PROCAFÉ.

os PROCAFÉ, (2011) Pronóstico final de producción de Café Año Cosecha 2011/2012. Edición de Fundación Salvadoreña para Investigaciones del Café, La Libertad. Oficina central de fundación PROCAFÉ.

os PROCAFÉ. Rejuvenezca su cafetal: pode cafetos y vuélvalos productivos. Hoja técnica. El Salvador. Edición de Fundación Salvadoreña para Investigaciones del Café, La Libertad. Oficina central de fundación PROCAFÉ.

os Programa Salvadoreño de Investigación sobre Desarrollo y Medio Ambiente (1993) Estudio del sector cafetalero de El Salvador, San Salvador.

os Ricardo, D. (1959) Principios de economía política y tributación. Tercera edición. Madrid, Aguilar.

os Rubio, R. (1979) Las formas generales de dominio del capital sobre el trabajo dentro de la agricultura salvadoreña. Tesis de licenciatura, Antiguo Cuscatlán. Departamento de Economía, Universidad Centroamericana "José Simeón Cañas".

os Screpanti, E. (1997) Panorama de historia del pensamiento económico. No definido. Barcelona. ARIEL.

os Montes, S. (1986) "El Salvador: La tierra y el epicentro de las crisis", Disponible en http://www.uca.edu.sv/boletines/upload_w/file/boletines /4fe212858da23elsalvador.pdf

os Smith, A. (1987) La riqueza de las naciones. Primera edición. Madrid, Alianza.

os TECHNOSERVE (2008) Diagnóstico sobre el consumo de café en El Salvador. Presentado al Consejo Salvadoreño del Café. El Salvador.

os USDA (2011) Coffee: World Markets and Trade. Foreign Agricultural Service. Circular Series. Office of Global Analysis.

os Rivas Arevalo, E. G., Rubio Mena, J. A. \& Zetino Valencia, E. R., (2011) Diseño de procedimientos para el costeo de los inventarios bajo el sistema de inventarios perpetuos, según normas internacionales de información financiera, aplicable a las empresas beneficiadoras de café en el dpto. de Santa Ana. San Salvador: s.n. 
os Van der Hayden, D. (2004) Guía metodológica para el análisis de cadenas productivas. Ruralter. Primera edición. Lima. Editorial Línea Andina S.A.C

os Zuñiga, R. y Rodríguez, W. (2002) El conglomerado de Café en El Salvador: Diagnóstico Competitivo y Recomendaciones. Documento en proceso. El Salvador. Centro Latinoamericano para la Competitividad y el Desarrollo Sostenible (CLADS) del INCAE.

\section{Notas}

1 La información estadística únicamente pudo obtenerse para las cooperativas del sector reformado.

2 Las labores productivas de café que implican desembolsos salariales de los patronos a sus empleados no se extienden durante todo el año. Por tanto, se ha estimado que el grueso de los empleos generados y salarios pagados son seis meses del total del año cosecha.

3 Según la DIGESTYC, la familia rural tiene un promedio de 4.3 miembros para 2011.

4 La metodología en que se basan los siguientes cálculos es desarrollada por Arriola y Candray (1991) y expuestas en Montoya (1998).

5 El Excedente Bruto de Explotación hace las veces de una aproximación a la masa de plusvalía, mientras que la masa salarial es lo que se le paga al trabajador, la masa salarial es lo que reciben los trabajadores y, por tanto, la suma de ambas variables resulta en el valor agregado de la producción cafetalera.

6 El tipo de cambio $(\$ / \mathbb{W})$ para 1989 fue de $5.60 ; 1990,7.60 ; 1991,8.00 ; 1992$, 8.37; 1993, 8.7; 1994-2010, 8.75 .

7 Una tasa de explotación que indica la obtención de US\$1.38 de ingreso por cada dólar pagado en concepto de salario.

8 Es necesario recordar que para el capitalista todo salario pagado se asumen como costo; por tanto, si paga por debajo del valor de la fuerza de trabajo, entonces tiene un ingreso adicional $\mathrm{o}$, al menos, no está desembolsando lo que debería para asegurar la reproducción de la fuerza de trabajo. Esta última asume esas necesidades no cubiertas y busca aliviarlas; estos esfuerzos son un ahorro para el capitalista, que puede despreocuparse de estos procesos de reproducción.

9 En un sistema capitalista los salarios relativos tienden a crecer menos que el grado de proletarización de la fuerza de trabajo, según la ley de la tendencia decreciente de salarios relativos formulados por Luxemburgo (Guerrero, 2000; citado en García, et al, 2011).

10 Para efectos de análisis, se asume que cada finca es poseída por un productor, facilitando el análisis microeconómico de familias que dependen de un productor con su finca. Además, las fincas que son poseídas por cooperativas entran en el análisis solamente como una finca de un solo productor, y no como un grupo de propietarios.

11 Con base en investigación obtenida de técnicos de PROCAFE, se ha consensuado que un pequeño productor está en la capacidad de cultivar y cosechar 
desde 0.01 hasta 10 manzanas utilizando su propia mano de obra y/o mano de obra familiar.

12 El valor del índice de Gini se sitúa entre 0 y 1 , siendo cero una situación de equidistribución del ingreso; y uno, lo contrario. Para el caso, se ha adaptado el índice y metodología para medir la situación de la distribución de la tierra.

13 Para aclaración de las cifras estadísticas y tratamiento metodológico, refiérase al documento completo

14 Pequeño productor, entrevistado personalmente por Katherine Chiquillo en viaje de campo.
15 Para las explotaciones entre cero y tres manzanas se han tomado en cuenta los costos por recolección, transporte y gastos financieros; para las explotaciones entre tres y diez manzanas, a aquellos se añaden los costos de insumo, siendo que para ambos tamaños de explotación no se toma en cuenta el costo de mano de obra ni de recolección, por ser asumidos en el núcleo familiar. Aunque es importante como costo de oportunidad y se debe contabilizar, para efectos del flujo de ingresos recibido, se han obviado.

16 Para una definición del término, referirse al apartado 1.7.2 del capítulo teórico del estudio completo. 